
4

(2)

(1)

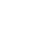

\title{
3D Multi-source Model of Elastic Volcanic Ground Deformation
} (1)

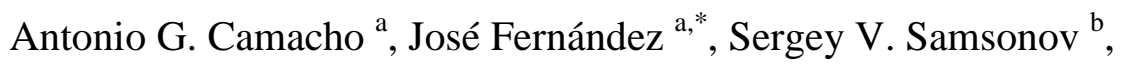
Kristy F. Tiampo ${ }^{\mathrm{c}}$, and Mimmo Palano ${ }^{\mathrm{d}}$

${ }^{a}$ Institute of Geosciences (CSIC-UCM), C/ Doctor Severo Ochoa, 7, Facultad de Medicina (Edificio entrepabellones 7 y 8, $4^{a}$ planta), Ciudad Universitaria, 28040, Madrid, Spain. (email: antonio_camacho@mat.ucm.es,jft@mat.ucm.es)

${ }^{b}$ Canada Centre for Mapping and Earth Observation, Natural Resources Canada, 560 Rochester Street, ON K1A 0E4, Ottawa, Canada. (e-mail: sergey.samsonov@canada.ca) ${ }^{c}$ CIRES and Geological Sciences. 216 UCB, University of Colorado, Boulder, CO 80309, USA. (e-mail: kristy.tiampo@colorado.edu)

${ }^{d}$ Istituto Nazionale di Geofisica e Vulcanologia, Osservatorio Etneo - Sezione di Catania, Piazza Roma 2, 95125 Catania, Italy (e-mail: mimmo.palano@ingv.it)

*Corresponding author: jft@mat.ucm.es, +34-913944632 (JF)

Keywords: 3D Model; multi-source; elastic medium; ground deformation. 
ABSTRACT: Developments in Interferometric Synthetic Aperture Radar (InSAR) and GNSS

(Global Navigation Satellite System) during the past decades have promoted significant advances in geosciences, providing high-resolution ground deformation data with dense spatio-temporal coverage. This large dataset can be exploited to produce accurate assessments of the primary processes occurring in geologically active areas. We present a new, original methodology to carry out a multi-source inversion of ground deformation data to better understand the subsurface causative processes. A nonlinear approach permits the determination of location, size and three-dimensional configuration, without any a priori assumption as to the number, nature or shape of the potential sources. The proposed method identifies a combination of pressure bodies and different types of dislocation sources (dipslip, strike-slip and tensile) that represent magmatic sources and other processes such as earthquakes, landslides or groundwater-induced subsidence through the aggregation of elemental cells. This approach has the following features: (1) simultaneous inversion of the deformation components and/or line-of-sight (LOS) data; (2) simultaneous determination of diverse structures such as pressure bodies or dislocation sources, representing local and regional effects; (3) a fully 3D context; and (4) no initial hypothesis about the number, geometry or types of the causative sources is necessary. This methodology is applied to Mt. Etna (Southern Italy). We analyze the ground deformation field derived from a large InSAR dataset acquired during the January 2009 - June 2013 time period. The application of the inversion approach models several interesting buried structures as well as processes related to the volcano magmatic plumbing system, local subsidence within the Valle del Bove and seaward motion of eastern flank of the volcano. 


\section{Introduction.}

Recent technical developments in geodesy have resulted in significant advances in volcanology (Fernández et al., 2017; and references therein). For example, Global Navigation Satellite System (GNSS) produced sub-centimeter precision in positioning while the development of Advanced Differential Interferometric Synthetic Aperture Radar (A-DInSAR) techniques have resulted in the estimation of $1 \mathrm{D}$ to $3 \mathrm{D}$ deformation field with dense spatiotemporal coverage. Therefore, high resolution, high precision measurements of ground deformation with extensive coverage are available to explore complex models of ground deformation in volcanic areas.

In this context, surface displacements are inverted to infer valuable constraints on the active magmatic sources (e.g., Rymer and Williams-Jones, 2000; Fernández et al., 2001; Dzurisin, 2007; Cannavò et al., 2015). Surface deformation is a direct consequence of the dynamics of volcanic plumbing systems, and reflect the shape of magma intrusions, the volume of intruding/arising magma, and the emplacement mechanisms. Normally, regular geometries (point sources, disks, prolate or oblate spheroids, etc.) are assumed at the initial stages (Lisowski, 2007) and the resulting inversion is carried out in a linear context.

Surface deformation also has been inverted in order to provide insight into the geometry and slip of buried seismic dislocations. The initial geometry of the buried dislocation is generally assumed based on prior information obtained from various sources such as local geology, fault mapping, and earthquake focal mechanisms. Again, the inversion is generally conducted in a linear framework (Segall, 2010; Pascal et al., 2014).

Camacho et al. (2011a) developed an original methodology aimed at the determination of the 3D geometry and the location of the causative bodies by inverting ground deformations and gravity changes due to pressure and/or mass anomalies embedded into an elastic medium. Such a fully nonlinear inversion has led to interesting results in volcanic environments, where 
ground deformations are related to over-pressured magmatic bodies (Camacho et al., 2011a; Samsonov et al, 2014; Cannavò et al, 2015; Camacho et al., 2018; Camacho and Fernández, 2019).

Most volcanically active regions are characterized by complicated patterns of ground deformation resulting from multiple natural (e.g., inflation, deflation, dike intrusion, active faulting, flank instability and landslides) and anthropogenic sources (Fernández et al., 2005, 2017; Tiampo et al., 2013; Samsonov et al., 2014). For example, Mt. Etna volcano is characterized by short-term inflation/deflation episodes related to the magmatic dynamics of its plumbing system, by a near-continuous seaward motion of its eastern flank (Palano, 2016) and by regional tectonic processes (Palano et al., 2012).

An extension of the former successful nonlinear approach, which only estimated elastic deformation due to pressure sources applicable to specific volcanic areas, is required for more general geophysical active regions, where more varied types of deformation sources are present.

We present a new inversion process that extends the previous methodology by including dislocation sources as given by Okada (1985), in order to obtain a more general inversion method that estimates non-subjective models of the observed deformation process within an almost entirely automatic framework.

Here, we describe this new approach, some simulation cases, and its application to actual ground deformation at Mt. Etna estimated from advanced A-DInSAR data. A second test case, the interpretation of the co-seismic deformation for the 2014 earthquake in Napa Valley (California) (Polcari et al., 2017), is presented in the Supplementary Material. The results allow us to evaluate the power of the methodology for 3D multi-source modelling of volcanic deformation data. 


\section{Inversion Methodology.}

101 Camacho et al. (2011a) presented an original methodology for simultaneous inversion of 102 displacement determined using terrestrial and/or space techniques and gravity changes, 103 adapted from a previous methodology for gravity inversion (Camacho et al, 2007 and 2011b).

104 Assuming simple isotropic elastic conditions, the approach determines a general geometrical 105 configuration of pressurized and/or density sources corresponding to prescribed values of 106 anomalous density and pressure. These sources are described as an aggregate of pressure and 107 density point sources, and they fit the entire dataset within some regularity conditions. In this 108 methodology, the representation of single sources as the sum of elementary solutions 109 representing 3D irregular geometries, as is typically done for dislocation sources representing 110 faults (Segall, 2010). For pressure sources, this is applied by assuming that the model is linear

111 in the pressure perturbation, with an assumed constant value of pressure change, and the 112 media is assumed to be isotropic, allowing for superposition (Geerstma and Van Opstal, 1973;

113 Brown et al., 2014; Fernández et al., 2018). In a mathematical appropriate way, pressure and 114 mass sources can be combined together (Rundle, 1982; Fernández and Rundle, 1994). The 115 approach works in a step-by-step growth process that constructs very general geometrical 116 configurations (Camacho et al., 2007; 2011a, b).

117 This approach provided useful results for volcanic areas when deformations come from 118 magmatic sources considered as a combination of pressure and mass variations, if 119 displacement and gravity change data are available; or just pressure sources if only 120 displacement data exist. Nevertheless, for many volcanic regions, observed deformations 121 often are caused by additional phenomena not related to pressurization. These include fault 
dislocations, sliding and subsidence phenomena that cannot be satisfactorily modelled with

123 the former approach. Therefore, here we propose an improvement of the original inversion methodology which incorporates these new sources, allowing us to obtain a general model of

125 all the observed deformation composed of multiple simultaneous and combined 3D sources.

126 In this new approach, superposition is still allowable for modeling single sources, as in

127 Camacho et al. (2011a). For combination of different sources of the same or different nature,

128 we apply the results of Pascal et al. (2014).

129 The medium is divided into a 3D partition of elemental cells. The aggregation of

130 elemental sources and the superposition of their contribution forms the geometry of the

131 extended causative bodies. One key aspect is to select some simple expressions for cell

132 contribution in order to fit thousands of data points by the superposition of thousands of cells

133 in a short time, thus allowing the methodology to be used for real time monitoring during

134 unrest (Cannavò et al., 2015; Camacho and Fernández, 2019).

\subsection{Elementary sources. Direct formulae.}

136 We consider a point $P(\mathrm{X}, Y, Z)$ located on the surface of a semi-infinite elastic medium

137 where an elemental source is located at $(x, y, z)$. For the surface deformation due to elemental

138 dislocation sources we use the expressions by Okada (1985), and for the elemental pressure

139 sources we use the expressions by Geertsma and Van Opstal (1973).

\section{2.1.1. Surface deformation due to shear and tensile elemental dislocations.}

141 Displacements $u_{x}, u_{y}, u_{z}$ at $P$ produced by a buried dislocations point source located at $142(x, y, z)$ in an elastic half-space are given by (Okada, 1985):

143 (a) for strike-slip: 


$$
\left(\begin{array}{l}
u_{x} \\
u_{y} \\
u_{z}
\end{array}\right)=-\frac{U_{1} \Delta S}{2 \pi}\left[\frac{3 d x q}{R^{5}}\left(\begin{array}{l}
d x \\
d y \\
d z
\end{array}\right)+\sin \delta\left(\begin{array}{l}
I_{1} \\
I_{2} \\
I_{4}
\end{array}\right)\right]
$$

145 (b) for dip-slip:

146

$$
\left(\begin{array}{l}
u_{x} \\
u_{y} \\
u_{z}
\end{array}\right)=-\frac{U_{2} \Delta S}{2 \pi}\left[\frac{3 p q}{R^{5}}\left(\begin{array}{l}
d x \\
d y \\
d z
\end{array}\right)-\sin \delta \cos \delta\left(\begin{array}{l}
I_{3} \\
I_{1} \\
I_{5}
\end{array}\right)\right]
$$

(c) for tensile:

148

$$
\left(\begin{array}{l}
u_{x} \\
u_{y} \\
u_{z}
\end{array}\right)=-\frac{U_{3} \Delta S}{2 \pi}\left[\frac{3 q^{2}}{R^{5}}\left(\begin{array}{l}
d x \\
d y \\
d z
\end{array}\right)-\sin ^{2} \delta\left(\begin{array}{l}
I_{3} \\
I_{1} \\
I_{5}
\end{array}\right)\right]
$$

where:

$$
\left(\begin{array}{l}
d x \\
d y
\end{array}\right)=\left(\begin{array}{cc}
\sin \alpha & \cos \alpha \\
-\cos \alpha & \sin \alpha
\end{array}\right)\left(\begin{array}{l}
X-x \\
Y-y
\end{array}\right)
$$

$$
\begin{aligned}
& d z=Z-z, \\
& I_{1}=\frac{\mu}{\lambda+\mu} d y\left[\frac{1}{R(R+d z)^{2}}-d x^{2} \frac{3 R+d z}{R^{3}(R+d z)^{3}}\right] \text {, } \\
& I_{2}=\frac{\mu}{\lambda+\mu} d x\left[\frac{1}{R(R+d z)^{2}}-d y^{2} \frac{3 R+d z}{R^{3}(R+d z)^{3}}\right] \text {, } \\
& I_{3}=\frac{\mu}{\lambda+\mu} d x\left[\frac{1}{R^{3}}\right]-I_{2}, \\
& I_{4}=\frac{\mu}{\lambda+\mu}\left[-d x d y \frac{2 R+d z}{R^{3}(R+d z)^{2}}\right] \text {, } \\
& I_{5}=\frac{\mu}{\lambda+\mu}\left[\frac{1}{R(R+d z)}-d x^{2} \frac{2 R+d z}{R^{3}(R+d z)^{2}}\right], \\
& \left(\begin{array}{l}
p \\
q
\end{array}\right)=\left(\begin{array}{cc}
\sin \delta & \cos \delta \\
-\cos \delta & \sin \delta
\end{array}\right)\left(\begin{array}{l}
d z \\
d y
\end{array}\right),
\end{aligned}
$$




$$
R^{2}=(X-x)^{2}+(Y-y)^{2}+(Z-z)^{2}=d x^{2}+d y^{2}+d z^{2}=d x^{2}+q^{2}+p^{2} .
$$

154

\subsubsection{Surface deformation due to a pressure elemental prismatic body.}

$$
\text { The simplest method which still provides a good overall estimate of the spatial subsidence }
$$

distribution for compacting reservoirs of arbitrary 3D shape and change in reservoir pressure is based on the lineal elastic theory of nuclei of strain in the half-space (Geertsma and Van Opstal, 1973). Assuming linearity of the stress-strain relation and isotropy of the material, the displacements $u_{x}, u_{y}, u_{z}$ at a surface point $P$ due to a buried small prismatic source with overpressure $\Delta p$ and sides $\Delta x, \Delta y, \Delta z$, located at $(x, y, z)$ in an elastic half-space can be determined as:

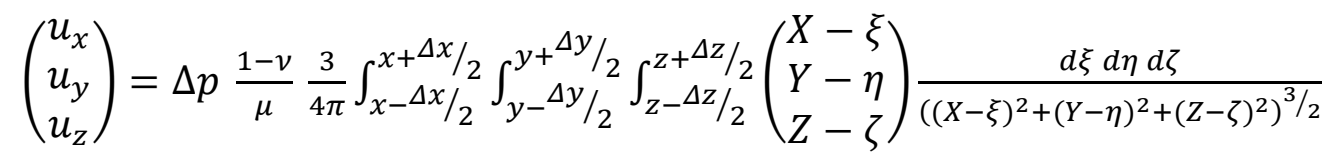

where $v$ is the Poissson's ratio and $\mu$ is the shear modulus.

Assuming that displacements $u_{x}, u_{y}, u_{z}$ at the surface happen to be almost directly proportional to the thickness $\Delta z$ of the reservoir, the volume integrations for a parallelepiped cell of sides $\Delta x, \Delta y, \Delta z$ and overpressure $\Delta p$ in equations (4) can be simplified to integration in the horizontal plane only given rise to (Geertsma and Van Opstal, 1973):

$$
\left(\begin{array}{l}
u_{x} \\
u_{y} \\
u_{z}
\end{array}\right)=\Delta p \frac{1-v}{\mu} \frac{3}{4 \pi} I \Delta z
$$

where: 


$$
I_{x}(p, q, r)=\operatorname{arcsinh} \frac{p}{\sqrt{q^{2}+r^{2}}}
$$

$$
I_{y}(p, q, r)=\operatorname{arcsinh} \frac{q}{\sqrt{p^{2}+r^{2}}}
$$

Equations (1)-(3), (5) provide the surface displacement due to elemental cells for pressure and dislocations. The total effect of a single anomalous structure described as an aggregation of $m$ small parallelepiped cells is obtained as an addition (discrete integration) of the partial effects (Geertsma and Van Opstal, 1973; Okada, 1985).

The topography of volcanoes can have an important effect on deformation changes (Supplementary Material). We take this effect into account by incorporating the varyingelevation analytical solution approach (Williams and Wadge, 1998) into the equations and code. This direct formulation is used to carry out the inverse approach and to determine the pressure and dislocation 3D source structures responsible of the observed deformation.

\subsection{Inversion methodology}

The perturbing 3D sources are described as an aggregate of elemental sources that fits the entire dataset within some regularity conditions. The approach works in a step-by-step growth process (Camacho et al., 2007; 2011b) constructing very general geometrical configurations.

The observation equations are:

$$
d r=d r^{c}+\varepsilon
$$

191 where $\boldsymbol{d} \boldsymbol{r}, \boldsymbol{d} \boldsymbol{r}^{\boldsymbol{c}}$ represent the vector of observed and calculated 3D displacements, and $\boldsymbol{\varepsilon}$ the

192 residual values coming from inaccuracies in the observations and from insufficient model fit.

In Camacho et al. (2011a), the surface deformations, $\boldsymbol{d r}^{\boldsymbol{c}}$, due to a buried over pressure

194 structure are calculated aggregating the effects for several Mogi point sources (Masterlark, 
195 2007). In the present paper $\boldsymbol{d} \boldsymbol{r}^{\boldsymbol{c}}$ corresponds to the addition of the pressure sources and the

196 Okada's dislocation sources (strike-slip, dip-slip and tensile). Moreover, we substitute the 197 simple point source calculus (Masterlark, 2007) by the more accurate calculus by Geertsma 198 and Van Opstal (1973) for 3D pressure structures.

\subsubsection{Model description.}

General geometrical single structures will be described by aggregation of elementary sources filled with causative perturbations (pressure, and strike-slip, dip-slip and tensile dislocations). We consider a partition of the medium into a dense 3D grid of $m$ small cells located in $\left(x_{i}, y_{i}, z_{i}\right)$ and with small volumes $\Delta V_{i}=\Delta x_{i} \cdot \Delta y_{i} \cdot \Delta z_{i}$ and small dislocation surfaces $\Delta S i, i=1, \ldots, m$. The data spatial resolution conditions the smaller cell size. Each small cell effect can be modeled by the effect of an elementary source located in its geometric center. We carry out the partitioning by means of small rectangular prisms on horizontal layers, looking for a similar average quadratic deformation effect of each cell upon the whole data set. Then, we calculate the deformation effects, $\boldsymbol{d} r_{j}\left(d X_{j}, d Y_{j}, d Z_{j}\right)$ (see Figure 1), in the $n$ surface (not necessarily gridded) points, $P_{j}\left(\mathrm{X}_{j}, Y_{j}, Z_{j}\right)(j=1, \ldots, n)$ by accumulation of the effects of the filled cells (for $i \in \operatorname{set} \Phi_{P}$ of pressured, $i \in \operatorname{set} \Phi_{S}$ of strike dislocation cells, $i \in \operatorname{set} \Phi_{D}$ for dip-slip and thrust dislocation cells, and $i \in \operatorname{set} \Phi_{T}$ for tensile dislocation cells):

$$
\boldsymbol{d r}^{c}=\sum_{\Phi P}\left(\begin{array}{l}
u_{x} \\
u_{y} \\
u_{z}
\end{array}\right)+\sum_{(\Phi S, \Phi D, \Phi T)}\left(\begin{array}{l}
u_{x} \\
u_{y} \\
u_{z}
\end{array}\right)
$$

$$
d r_{j}^{c}=\sum_{i \epsilon \Phi_{P}} \Delta V_{i} \Delta \rho_{i} f_{p}\left(r_{i j}\right)+\sum_{i \epsilon \Phi_{S}} \Delta S_{i} \Delta \sigma_{i} f_{S}\left(r_{i j}, \alpha_{i}, \delta_{i}\right)+\sum_{i \epsilon \Phi_{D}} \Delta S_{i} \Delta \sigma_{i} f_{D}\left(r_{i j}, \alpha_{i}, \delta_{i}\right)+
$$

$$
\sum_{i \in \Phi_{T}} \Delta S_{i} \Delta \sigma_{i} f_{T}\left(r_{i j}, \alpha_{i}, \delta_{i}\right)
$$

$$
j=1, \ldots, n
$$

with $u_{x}, u_{y}, u_{z}$ given throw equations (1), (2), (3) and (5). 
Volumes $\Delta V_{i}$, surfaces $\Delta S_{i}$ and intensity factors $\Delta \rho_{i}$ (pressure, MPa) and $\Delta \sigma_{i}$ (dislocation, cm) appear as linear factors in the observation equations (6)-(8), allowing for simple cell aggregation, but the other model parameters (orientation angles $\alpha$ and $\delta$, and sets $\Phi_{P}, \Phi_{S}, \Phi_{D}$, and $\Phi_{T}$ of filled cells) are nonlinear, necessitating a non-linear inversion approach.

\subsubsection{Misfit conditions.}

Assuming a Gaussian uncertainty given by a covariance matrix $\boldsymbol{Q}_{\boldsymbol{D}}$ for displacement data, a minimization condition for observation residuals $\boldsymbol{\varepsilon}$, as $\boldsymbol{\varepsilon}^{T} \mathbf{Q}_{\mathbf{D}}^{-1} \boldsymbol{\varepsilon}=\min$, leads to the maximum likelihood solution. For a simplified treatment, $\boldsymbol{Q}_{\boldsymbol{D}}$ is considered as a diagonal matrix of estimated variances corresponding to the displacement data.

During inversion of geophysical data, problems of singularity and instability for the solution can arise due to inadequate data coverage (normally the number of data points is smaller than the number of unknowns), inaccuracy of the data, and intrinsic ambiguity of the design problem. In this case, they can occur if we assume that positive and negative anomalous pressure/dislocations can be contemporaneously present in the model. A process to avoid instabilities is to consider additional minimization or smoothing conditions for the norm

232 of the solution model as:

$$
\mathbf{m}^{T} \mathbf{Q}_{M}^{-1} \mathbf{m}=\min
$$

234 where the vector $\boldsymbol{m}$ is constituted by the values $\Delta \rho_{i}$ and $\Delta \sigma_{i}(\mathrm{i}=1, \ldots, m)$ for the filled cells of 235 the model (sets $\Phi_{P}, \Phi_{S}, \Phi_{D}$, and $\Phi_{T}$ ) and $\boldsymbol{Q}_{\boldsymbol{M}}$ is a suitable covariance matrix corresponding to 236 the physical configuration of cells and data points. This matrix provides a balanced model, 237 avoiding very shallow solutions. We propose a normalizing diagonal matrix $\boldsymbol{Q}_{\boldsymbol{M}}$ with elements 238 $q_{i}(i=1, \ldots, m)$ given for volumes $\Delta V_{i}$ and distances $r_{i j}$ as 


$$
q_{i}=\frac{\Delta V_{i}}{n} \sum_{j=1}^{n} \frac{\left|z_{j}-Z_{i}\right|}{r_{i j}^{3}}
$$

240 that takes into account the average effect of the $i$-th cell upon all data points.

241 Condition (9) is a stabilizing term for control on the entire pressure, and dislocations of the 242 structures (Farquharson and Oldenbourg, 1998; Bertete-Aguirre et al., 2002). Weighting by 243 matrix $\boldsymbol{Q}_{M}$ prevents the occurrence of very large fictitious values of pressure/dislocations, 244 resulting from a model that is poorly determined model due, e.g., to coupling of some positive 245 and negative sources, peripheral sources, etc.

Finally, a mixed minimization equation

$$
S(\mathbf{m})=\boldsymbol{\varepsilon}^{T} \mathbf{Q}_{D}^{-1} \boldsymbol{\varepsilon}+\gamma \mathbf{m}^{T} \mathbf{Q}_{M}^{-1} \mathbf{m}=\min .
$$

is adopted for the constraining equation (6) for residuals and for model magnitude. $\gamma$ is a

249 factor that provides a balance between fitness and smoothness of the model. Low $\gamma$ values 250 produce very good data fit but often result in extended and/or irregular models. Conversely, 251 high $\gamma$ values can produce concentrated and smooth models but with a poorer data fit. The optimal choice is determined by an autocorrelation analysis of the residual values, the value producing a null (planar) autocorrelation distribution (Moritz, 1980; Camacho et al., 2007).

\subsubsection{Exploration approach for solving the system.}

The model system (6)-(8) must be satisfied within the minimization constraint condition (11). It constitutes a nonlinear optimization problem with respect to the geometrical properties (orientation angles $\alpha$ and $\delta$ for the dislocations, and sets $\Phi_{P}, \Phi_{S}, \Phi_{D}$, and $\Phi_{T}$ of filled cells).

Considering the very large number of degrees of freedom necessary to describe the 
ineffective. A necessary reduction of the model space is obtained by limiting the possible 262 orientation angles (dip $\delta$ and azimuth $\alpha$ ), considering only certain orientations. We limit values of $\alpha$ from $0^{\circ}$ to $180^{\circ}$, and of $\delta$ from $0^{\circ}$ to $90^{\circ}$, with step $10^{\circ}$, resulting in 190 possible orientations for each elemental dislocation. After tests on simulated and real data we have concluded that this offers enough detail for most practical applications. Any arbitrary dislocation direction can be fit by a combination of these basic directions.

The model space to be explored is composed by: (1) $m$ possible cells to be filled; (2) four 268 primary source possibilities (pressure change, strike, dip or tensile dislocation) for each cell; (3) positive or negative value for each pressure/dislocation cell; and (4) 190 possible orientations for dislocation elements. As previously pointed, coefficients $\Delta V_{i}, \Delta S_{i}, \Delta \rho_{i}$ and $271 \Delta \sigma_{i}$ appear in linear mode and they are solved by a scaled, linear fit.

Despite the reduction in angular options, a general exploration of the extensive model domain that considers all possible combinations of thousands of cells, and angles, signs, and source natures, would be inefficient. An alternative approach is to build the anomalous 3D structures by means of a step-by-step growth process. The key idea is to substitute a unique global exploratory approach by successive explorations. For each step of the growth process, that exploration allows for selection of only one new optimal cell (and additional parameters) (Camacho et al., 2007; 2011b). This approach explores a model domain clearly smaller at every step, composed only of the "empty" cells.

Further, we assume that pressure values $(\Delta \rho)$ and dislocation amplitude values $(\Delta \sigma)$ will be the same over the entire model. These will be expressed as proportional to some basic fixed 282 values $\Delta \rho_{o}$ and $\Delta \sigma_{o}, \Delta \rho=f \times \Delta \rho_{o}$ and $\Delta \sigma=f \times \Delta \sigma_{o}, f>0$ being a scale factor. $\Delta \rho_{o}$ and $\Delta \sigma_{o}$ are 283 arbitrary small fixed values with a fixed ratio $\Delta \rho_{o} / \Delta \sigma_{o}$ so that the average effect upon the data 284 of an arbitrary cell with dislocation $\Delta \sigma_{o}$ will be similar to the one of a pressure arbitrary cell 285 with pressure $\Delta \rho_{o}$. 

step of the growth process, $k$ cells have been filled with the prescribed anomalous values for pressure $\Delta \rho_{o}$ and dislocation amplitude $\Delta \sigma_{o}$, giving rise to modeled values $\boldsymbol{d} \boldsymbol{r}^{c}$ from the model equations, which now include a scale factor. For the $(k+1)$-th step, we fill a new cell fitting the system,

$$
\begin{gathered}
\boldsymbol{d} \boldsymbol{r}=f_{k+1} \boldsymbol{d} \boldsymbol{r}^{c}+\boldsymbol{\varepsilon} \\
\boldsymbol{\varepsilon}^{T} \boldsymbol{Q}_{\mathrm{D}}^{-1} \boldsymbol{\varepsilon}+\gamma f_{k+1}^{2} \boldsymbol{m}^{T} \boldsymbol{Q}_{M}^{-1} \boldsymbol{m}=\min
\end{gathered}
$$

where $0<f_{k+1}<f_{k}$ is a scale factor that fits the modeled deformation field for the provisional, not fully developed, model and the observed deformations. We calculate the value $e^{2}=\boldsymbol{\varepsilon}^{T} \boldsymbol{Q}_{\mathrm{D}}^{-1} \boldsymbol{\varepsilon}+\gamma f_{k+1}{ }^{2} \boldsymbol{m}^{T} \boldsymbol{Q}_{\mathrm{M}}^{-1} \boldsymbol{m}$ for the empty cells according to a general exploratory approach with random selection. We choose as optimal cell to be filled for the $(k+1)$-th step that $j$-th cell giving:

$$
e_{j}^{2}=\min .
$$

Throughout the process both $f$ and $e^{2}$ decrease. Note that considering the scale factor $f$ modifies the process from a unique general exploration of the extensive model domain, which would be inefficient, to a much more affordable task: the exploration of aggregation possibilities for a new cell, in a step-by step growth process. This is the primary feature of the inversion approach.

The process continues until: (1) $f$ reaches a prescribed small value according to a defined criterion based on previous trials and inspection of the resulting model; or (2) aggregation of a new cell does not produce smaller values of $f$ and $e^{2}$. Case (2) produce the larger model, with smaller values for $\Delta \rho$ and $\Delta \sigma$. One potential definition of the stopping criteria could be a 308 prescribed ratio between successive $e^{2}$ values. 
At the final step, we arrive at a 3D model virtually automatically. That model is the aggregation of some filled elementary cells: (1) pressure elementary sources filled with the prescribed anomalous values; and (2) dislocation elementary sources with the appropriate orientation and magnitude. Together, they fit the observed displacement within some error margin and appropriate set of model bounds.

314 A final test on the validity of the inversion results is done by comparing their geographical 315 distribution and distances between differences sources, as in Pascal et al. (2014).

316 Additional details about the practical implementation of the inversion approach are described in Section B of the Supplementary Material.

\section{Synthetic test cases.}

To demonstrate the efficiency of this inversion process, we consider a simulated example described in Figure 2, composed of four different deformation sources: a vertical ellipsoid with homogeneous negative pressure (-3 MPa located at $2.5 \mathrm{~km}$ depth below the surface and 322 with semi-axes of $2 \mathrm{~km}$ and $1.4 \mathrm{~km}$ ) (Figure 2a); a sub-horizontal strike-slip fault (azimuth $65^{\circ}$ and dip angle $20^{\circ}$ from the horizontal, length $5 \mathrm{~km}$ and width $3 \mathrm{~km}$, located at $1.5 \mathrm{~km}$ depth) with $12 \mathrm{~cm}$ dislocation (Figure 2b); a nearly vertical dip-slip fault (azimuth $30^{\circ}$ and tilt angle $20^{\circ}$ from the vertical, $4 \mathrm{~km}$ vertical side and $7 \mathrm{~km}$ horizontal side, mean depth $2.5 \mathrm{~km}$ 326 below the surface) with $9 \mathrm{~cm}$ dislocation (Figure 2c); and a tensile fault (azimuth $20^{\circ}$, tilt 327 angle $5^{\circ}$, dimensions $2 \mathrm{~km}$ and $4 \mathrm{~km}$, mean depth $2 \mathrm{~km}$ ) with $10 \mathrm{~cm}$ of opening (Figure $2 \mathrm{~d}$ ). 328 Above these buried anomalous structures, a planar distribution grid of 800 data points is 329 delineated, with a grid size of $400 \mathrm{~m}$ and total diameter of $12 \mathrm{~km}$ (Figure 3). The anomalous 330 pressure body, which is sensitive to the diameter of the survey area, occupies a central 331 position below the survey area. The fault structures are located in the borders of the survey 332 area. In this case, we employ a magnitude of $6 \mathrm{MPa}$ (for pressure) and $9 \mathrm{~cm}$ (for all 333 dislocation kinds). Figure 3 shows the (a) $U p$, (b) $E W$ and (c) $N S$ components of the simulated 
334 displacement vectors $\left(u_{x}, u_{y}, u_{z}\right)$ at the 800 surface points $\left(X_{i}, Y_{i}, Z_{i}\right)$. The average amplitudes

335 of these 800 data values are $2.1 \mathrm{~cm}, 1.2 \mathrm{~cm}$, and $1.4 \mathrm{~cm}$ respectively.

For the simulated data (Figure 3), we apply the inversion approach without any a priori assumptions about the 3D structure of the sources. First, we determine a complete 3D partition of the subsurface volume into several thousands of cells with mean side $170 \mathrm{~m}$

339 (Figure 1). The primary decision required concerns the $\gamma$ parameter. It is selected, after several 340 trials, as that larger value producing a (nearly) null autocorrelation distribution of the final 341 residues for the three components. A secondary assessment is made for the growth stopping 342 criteria. Here we employ a standard threshold value for the ratio $e_{k}^{2} / e_{k-1}^{2}$ between successive 343 values of the misfit parameter, given as a default value in our software. Once these are 344 selected, the 3D model for the deformation sources is obtained automatically. This resulting 345 model is composed of a large aggregation (thousands) of elementary (pressure and 346 dislocations) cells. Figure 3 (right) shows the fit between the simulated (orange) and modelled 347 (blue) data. That fit is quite good, about $0.01 \mathrm{~cm}$ for all three components.

348 Figure 4 shows a flat view from the top of the obtained 3D model defined by aggregation 349 of elemental deformation sources. They reproduce the simulated data (Figure 3) very well and 350 fit the original simulated, pressurized ellipsoid and faults, represented by dashes lines in 351 Figure 4, reasonably well, given that the inversion fit is unconstrained, and involves several 352 simultaneous possibilities for the active structures without specific a priori hypothesis about 353 the number, nature or shape of sources.

354 Considering these results, we outline some observations on the operation of this 355 methodology:

356 (1) The SE dipping fault structure appears well-constrained, almost entirely composed of 357 small dipping elements (yellow in Figures 4 and 5), whose aggregation describes an 358 extended body with geometry and location similar to the original body. As expected, 
considering the regularity conditions, the top of the structure is quite precise, but the bottom appears rounded and more diffuse.

(2) The pressure ellipsoidal structure also is well-characterized, composed largely of an show the inversion results for the former source bodies, but as isolated structures, and an isolated spherical source. These isolated studies offer better results that the former combined modelling. Second, we present different simulation studies for combinations of spherical pressurized bodies. Third, we repeat the previous synthetic case combining different 
384 Results show the efficiency in noise filtering, but they also show some deterioration of the

385 model due the noise effects. All this material provides an evaluation of the method's efficacy.

386 An additional consideration is that of the relative confidence corresponding to the fitted

387 model. First, a global confidence of the model comes, as previously pointed out, from the 388 study of the autocorrelation of the residuals and the choice of the value of the smoothing 389 parameter $\gamma$. Another interesting approach to the model confidence comes from a study of the 390 sensitivity of the data pixels to the different areas of the $3 \mathrm{D}$ model. Indeed, the model 391 characteristics (nature of the source, magnitude, orientation angles, sign) are identified with 392 varying clarity depending on the location of the cells within the subsurface volume and the 393 orientation of the dislocation sources. Cells located in very deep or peripheral areas with 394 respect to the pixels provide a smaller sensitivity and relative confidence (Supplementary 395 Material, Section E).

\section{Mt. Etna application case.}

Mt. Etna (Figure 6) constitutes an excellent test case for applying the inversion methodology detailed above. The volcano was characterized, over the past decade, by 399 persistent volcanic activity as well as a continuous seaward motion of its eastern flank (Palano, 2016). In addition, the large number of SAR images over the region provides a high quality dataset of ground deformation at the scale of the entire volcano. We perform an application of the inversion methodology without a priori assumptions on the numbers, type

403 and 3D geometry of the causative sources.

\subsection{Deformation data.}

To study ground deformation at Mt. Etna we collected 38 ascending and 59 descending

RADARSAT-2 Standard-3 (S3) images spanning the January 2009 - June 2013 period (see 
407 Figure 7, and Table S1, Supplementary Material, Section D). Each SAR dataset was 408 processed independently with the GAMMA software (Wegmuller and Werner, 1997). A 409 single master for each set was selected and remaining images were re-sampled into the master 410 geometry. The spatially averaged interferograms were computed and the topographic phase 411 was removed using the $30 \mathrm{~m}$ resolution Advanced Spaceborne Thermal Emission and 412 Reflection Radiometer (ASTER) Digital Elevation Model. Differential interferograms were 413 filtered using adaptive filtering with a filtering function based on local fringe spectrum 414 (Goldstein and Werner, 1998) and unwrapped using the minimum cost flow algorithm 415 (Costantini, 1998). The residual orbital ramp was corrected by applying a baseline refinement 416 algorithm implemented in GAMMA software. For this, the area experiencing large ground 417 deformation was masked out and baseline parameters were re-estimated from the 418 measurements of interferometric phase and topographic height. Minor interpolation of each 419 interferogram was performed in order to improve the spatial coverage reduced by 420 decorrelation. Then, 494 ascending and 298 descending interferograms were geocoded and 421 resampled to a common lat/long grid with the uniform spatial sampling (Table 1). The 422 advanced Multidimensional Small BAseline Subset (MSBAS) method (Samsonov and 423 d'Oreye, 2012; Samsonov et al., 2014) was employed to produce horizontal and vertical time series of ground deformation.

425 Several inflation/deflation episodes occurred during the 2009-2013 period. However, the 426 GNSS time series show a clear long-term trend, similar to the InSAR average deformation 427 rates. Therefore, as a first order approximation, use of the average deformation rates to 428 describe the long-term trend is justified. Working directly with ascending and descending $429 L O S$ displacements would avoid some uncertainties but it would make interpretation of results 430 significantly more tedious. Two-dimensional deformation rates produced by MSBAS can be 431 easily understood by any user, independently of their knowledge on InSAR. 
From the total dataset (approximately 451000 pixels) for both $U p$ and $E W$ components, we extract a reduced subset as input for the inversion approach. We use pixels which verify three conditions: located within $20 \mathrm{~km}$ distance from the Mt. Etna summit, with a distance between consecutive pixels of $800 \mathrm{~m}$, and with a coherence value higher than 0,6 . The result of this selection is a dataset of 1613 pixels (Figure 7). At this reduced size the inversion method runs

437 faster and the main features of the resulting model will be nearly the same that for the total 438 dataset (see Supplementary Material).

\subsection{Inverse modelling.} perturbations in the deformation data, such as inexact orientation or regional effects. In fact,

454 in such cases, the model will introduce fictitious sources, located in very shallow or very 455 peripheral locations, limiting distortion effects on the real sources. 
The resulting 3D model is composed of approximately 12,000 cells filled with one of the deformation elemental patterns: negative or positive pressure and/or dislocation (with values of about $0.5 \mathrm{MPa}$ and $2 \mathrm{~cm}$ ) for the available directions, plus several thousands of empty cells (see Figures 8-10).

\subsection{Discussion.}

The final cell aggregation appears as a rather complex model (Figure 8). However, by isolating subareas and dynamic components of this combined model, the resulting structures identify several interesting features and support several conclusions about the active sources below Mt. Etna volcano.

One important caution is that the input data correspond only to the $U p$ and $E W$ example of the efficiency and robustness of the method. A detailed discussion about the inversion results would be the objective of another paper. Below we briefly discuss the main sources of deformation inferred from our InSAR data modelling.

\subsubsection{Plumbing system.}

In Figure 9, we show some isolated source structures (pressure and tensile cells) that may

473 be related to the plumbing system of Mt. Etna. These appears to be composed of two echelon 474 pressurized reservoirs located at depths of approximately 3000 and $11000 \mathrm{~m}$ below sea level, 475 bsl, and a shallower SSW elongated dike structure at a mean depth of $1500 \mathrm{~km}$ bsl (Figures 8476 10). These plumbing structures are located below the western slope of the volcano edifice. 477 The deeper reservoirs are located progressively more SSW, suggesting an ancient location of 478 the eruptive system. Their overall shape and position correspond to the crustal volume where 479 a number of inflating/deflating sources, feeding the volcanic activity during 2009-2013, have 
been inferred by GNSS-based models (e.g. Patanè et al., 2013; Spampinato et al., 2015;

481 Cannata et al., 2015).

Curiously, the shallower structure connected with the plumbing system in this model is a tensile elongated structure (purple color in Figures 8-10), located at approximately $1500 \mathrm{~m}$ bsl, that seems to extend almost into the volcano summit. Considering that it is located in an area that is sensitive to this modelling method (Supplementary Material, Section E), we infer that it corresponds to dike structures, separate from the deeper reservoir structures that appears as pressurized cells. Such a structure aligns with the so called "West Rift", a zone of weakness on the western flank where numerous monogenetic pyroclastic cones are aligned along $240-260^{\circ} \mathrm{N}$ (e.g. Mazzarini and Armienti, 2001).

\subsubsection{Pernicana fault and sliding system.}

Our model also suggests a complex pattern of deformation on the eastern flank of the volcano. In the aggregation model shown in Figures 8 and 10, the main source components are cells for strike- and dip slip dislocations. There is a shallower strike system close to the Pernicana fault (Figure 6), which shows a tilted geometry (see Figure 10e) and a deeper subhorizontal central striking system at a depth about $4-5 \mathrm{~km}$ (Figure 10c). There is also a dipping system in three parts (Figure 10): (a) the shallow header of the downward sliding, 497 both close to the summit (Figure 10a), and inside Valle del Bove (Figure 9b), (b) an intense 498 downward dipping region at $4 \mathrm{~km}$ depth (Figure 10c), and (c) a third dipping zone (5 $\mathrm{km}$ 499 depth) that corresponds to the thrusting final section of the sliding system.

500 The strike cells largely correspond to sub-horizontal sliding, and the dip cells determine 501 the dipping pattern (normal in the header and Valle del Bove, and thrusting in the last half). 502 We observe that sub-horizontal dislocations dip and strike sources are combined, similar to 503 the synthetic case. 
This geometry is rather different from that proposed in the literature, resulting from geophysical-geochemical and magnetotelluric data (e.g. Siniscalchi et al., 2012) and geodetic inversion models (e.g., Palano, 2016 and references therein). The seaward motion of eastern flank of the volcano occurs along a shallow sliding surface bounded by the North Rift Pernicana fault system and the South Rift - Mascalucia - Tremestieri - San Gregorio Acitrezza fault system, northward and southward, respectively (e.g. Palano, 2016). Since no a priori constraints have been adopted during the inversion, the south-dipping planar surface resulting from the inversion probably represents an "average source" of the sub-horizontal sliding surface and the $\sim 60^{\circ}$ S-dipping Pernicana fault system. However, where the modelled planar dislocation intersects the volcano surface corresponds to the Pernicana fault system, capturing the boundary between the undeformed sector (northward of the fault) and the unstable region of the eastern flank of the volcano.

The localized subsidence structure below Valle del Bove, represented by dip cells and a depressurized body, may be related to: (i) the cooling and compaction of the lava flows that in the last decade accumulated on the western side of Valle del Bove (e.g. De Beni et al., 2015), and/or (ii) a process of relaxation of the substrate in response to loading produced by deposited lavas (e.g. Briole et al., 1997).

\section{Conclusions.}

We have presented a new inversion methodology for modeling geodetic displacement data in active volcanic areas which permits simultaneous inversion of the several components of surface deformations and allows for a global fit of the data. Non-planar and non-gridded data can be employed in this approach.

The method allows for objective modelling of diverse causative structures as pressure bodies, and general dislocations (strike-slip, dip-slip and tensile). Well-known analytical 
expressions from Okada (1985), for elemental dislocation sources, and Geertsma and Van

529 Opstal (1973), for pressured small prisms, are used for direct calculation. They assume a semi-infinite elastic medium, characterized by some values of the elastic parameters. The assumptions of linear elasticity and isotropy allows for the final modeling by superposition of effects for elemental components (prisms and dislocations) form the obtained aggregated geometry.

The approach works in a fully 3D context, although it employs, for faster operation, elementary dislocation sources limited to a discrete set of orientations. A free 3D geometry of the causative structures is described by aggregation of small elemental cells. There are not additional a priori requirements on the geometry and types of the causative sources. The 538 method is able to automatically determine the number, nature and $3 \mathrm{D}$ geometry of the 539 causative source structures, and supports different type of deformation data, such as 540 GNSS/GPS, InSAR (horizontal and vertical components, or ascending and/or descending LOS 541 data), leveling data, and others. The inversion process constitutes an interesting tool for 542 integrating simultaneously terrestrial and spatial data, providing mapped models which 543 incorporate all the available data.

This new methodology allows for a nearly automatic approach that takes advantage of 545 the large and precise datasets coming from ground-based deformation and advanced DInSAR 546 techniques and carries out an exhaustive inversion of ground deformation data to better 547 understand the subsurface causative structures and elastic processes, without preconceived 548 hypotheses. It can be applied on large regional scales to model tectonic plate movements and 549 subduction, volcanic activity and, on more local scales, to model deformation from landslides, 550 volcanic eruptions, and anthropogenic subsidence due to mining and extraction of oil, gas, or 551 groundwater. Additionally, this new inversion methodology can be used to invert coseismic 552 geodetic deformation data, as detailed in Section F, Supplementary Material. 
In particular, for the InSAR data of Mt. Etna 2009-2013, the application of this methodology resulted in a model for several subsurface sources corresponding to the plumbing system, the subsidence within Valle del Bove and the seaward motion of the eastern flank of the volcano.

Several precautions should be noted. First, as for other geophysical inversions, the problem has an intrinsic ambiguity. It is solved by use of regularity conditions. Solutions must

559 be interpreted carefully as informative models constrained by limitations in data and 560 smoothing constraints, particularly when applied, as here, within a range of potential 561 causative sources. Second, confidence in the solutions is not uniform. Peripheral or very deep 562 elements will be relatively less valuable (Supplementary Material, Section E). Third, in some 563 cases this approach allows for the separation of perturbing effects (noise, outliers, etc.) in the 564 deformation data.

Finally, there are some potential limitations on the validity of the results depending on 566 the combination and sizes of the detected sources. The resulting combination of 3D sources, 567 nature, geometries and relative distances should be examined for inconsistent results, as 568 described in Pascal et al. (2014).

\section{Acknowledgements}

570 This research has been primarily supported by the Spanish Ministerio de Ciencia, 571 Innovación and Universidades research project DEEP-MAPS (RTI2018-093874-B-I00) and 572 partially by the Spanish Ministry of Economy and Competitiveness research project 573 AQUARISK (ESP2013-47780-557-C2-1-R) and Thematic Network EPOS Spain (CGL2016574 81965-REDT), and the EU VII Framework Program, ESFRI, EPOS IP (676564-EPOS IP). 575 Research by KFT is funded by CIRES, University of Colorado Boulder. We thank M. Polcari 
and J. Escayo for providing the 3D coseismic deformation data for the 2014 Napa Valley earthquake. This is a contribution to the Moncloa Campus of International Excellence.

\section{References}

Bertete-Aguirre, H., Cherkaev, E. and Oristaglio, M. (2002), Non-smooth gravity problem with total variation penalization functional, Geophys. J. Int., 149, 499-507.

Briole, P., Massonnet, D., Delacourt, C. (1987), Post-eruptive deformation associated with the 1986-87 and 1989 lava flows of Etna detected by radar interferometry. Geophysical research Letters, 24, 37-40, doi:10.1029/96GL03705.

Brown, N. J., Woods, A. W., Neufeld, J. A. \& Richardson, C. (2014), Constraining Surface Deformation Predictions Resulting from Coal Seam Gas Extraction, https://doi.org/10.11636/Record.2014.044.

Camacho, A.G., Nunes, J.C., Ortiz, E., França, Z., and Vieira, R. (2007), Gravimetric determination of an intrusive complex under the Island of Faial (Azores): some methodological improvements, Geophys. J. Int., 171, 478-494.

Camacho, A.G., González, P.J., Fernández, J. and Berrino, G. (2011a), Simultaneous inversion of surface deformation and gravity changes by means of extended bodies with a free geometry: Application to deforming calderas, J. Geophys. Res., 116, B10401, doi:10.1029/2010JB008165.

Camacho, A.G., Gottsmann, J. and Fernández, J. (2011b), The 3-D gravity inversion package GROWTH2.0 and its application to Tenerife Island, Spain, Computer \& Geosciences, $37,621-633$ 
Camacho, A. G., Fernández, J. \& Cannavò, F. (2018), PAF: A software tool to estimate freegeometry extended bodies of anomalous pressure from surface deformation data. Comput. Geosci. 111, 235-243.

Camacho, A.G., Fernández, J. (2019), Modeling 3D free-geometry volumetric sources associated to geological and anthropogenic hazards from space and terrestrial geodetic data. Remote Sens., 11(17), 2042; https://doi.org/10.3390/rs11172042.

Cannata, A., G. Spedalieri, B. Behncke, F. Cannavò, G. Di Grazia, S. Gambino, S. Gresta, S. Gurrieri, M. Liuzzo, and M. Palano (2015), Pressurization and depressurization phases inside the plumbing system of Mount Etna volcano: Evidence from a multiparametric approach, J. Geophys. Res. Solid Earth, 120, doi:10.1002/2015JB012227.

Cannavò F., Camacho, A.G., González, P.J., Mattia, M., Puglisi, G. \& Fernández, J. (2015), Real Time Tracking of Magmatic Intrusions by means of Ground Deformation Modeling during Volcanic Crises. Scientific Reports, 5:10970, doi: 10.1038/srep10970.

Costantini, M (1998), A novel phase unwrapping method based on network programming. IEEE Transactions on Geoscience and Remote Sensing, 36(3):813-821.

De Beni, E., B. Behncke, S. Branca, I. Nicolosi, R. Carluccio, F. D’Ajello Caracciolo, and M. Chiappini (2015), The continuing story of Etna's New Southeast Crater (2012-2014): Evolution and volume calculations based on field surveys and aerophotogrammetry, J. Volcanol. Geotherm. Res., 303, 175-186, doi:10.1016/j.jvolgeores.2015.07.021.

Dzurisin D. (2007), A comprehensive approach to monitoring volcano deformation as a window on the eruption cycle, Rev. Geophys.,41(1), 1001, doi:10.1029/2001RG000107.

Farquharson, C.G., and Oldenbourg, D.W. (1998), Non-linear inversion using general measures of data misfit and model structure, Geophys. J. Int., 134, 213-227.

Fernández, J., and Rundle, J.B. (1994), Gravity changes and deformation due to a magmatic intrusion in a two-layered crustal model. Journal of Geophysical Research, 99, 27372746, doi: 10.1029/93JB02449. 
625 Fernández, J., Tiampo, K. F., Jentzsch, G., Charco, M., Rundle, J. B. (2001), Inflation or deflation? New results for Mayon volcano applying elastic-gravitational modeling. Geophysical Research Letters, 28, 2349-2352. DOI: 10.1029/2000GL012656.

Fernández, J., Romero, R., Carrasco, D., Tiampo, K., Rodriguez-Velasco, G., Aparicio, A., Araña, V., González-Matesanz, F. (2005), Detection of displacements in Tenerife Island, Canaries, using radar interferometry, Geophysical Journal International 160: $33-45$.

Fernández, J., Pepe, A., Poland, M.P., Sigmundsson, F. (2017), Volcano Geodesy: Recent developments and future challenges. Journal of Volcanology and Geothermal Research, 344, 1-12, doi: 10.1016/j.jvolgeores.2017.08.006.

Fernández, J., J. F. Prieto, J. Escayo, A. G. Camacho, F. Luzón, K. F. Tiampo, M. Palano, T. Abajo, E. Pérez, J. Velasco, T. Herrero, G. Bru, I. Molina, J. López, G. RodríguezVelasco, I. Gómez, J. J. Mallorquí (2018), Modeling the two- and three-dimensional displacement field in Lorca, Spain, subsidence and the global implications. Scientific Reports, 8:14782, https://www.nature.com/articles/s41598-018-33128-0.

Geertsma, J. \& Van Opstal, G. (1973), A numerical technique for predicting subsidence above compacting reservoirs based on the nucleus of strain concept. Verh. Kon. Ned. Geol. Mijnbouwk 28, 63-78.

Goldstein, R. and Werner, C. (1998), Radar interferogram filtering for geophysical applications. Geophysical Research Letters, 25(21):4035-4038.

Lisowski, M. (2007), Analytical volcano deformation source models, in Volcano Deformation, chap. 8, pp. 279-304, Springer Praxis, Chichester, U.K.

Masterlark, T. (2007), Magma intrusion and deformation predictions: Sensitivities to the Mogi assumptions, J. Geophys. Res., 112 (B06419), doi:10.1029/2006JB004860.

Mazzarini, F., and P. Armienti (2001), Flank cones at Mount Etna volcano: Do they have a power law distribution?, J. Volcanol. Geotherm. Res., 62, 420-430. 
651 Moritz, H. (1980). In: Herbert, W.V. (Ed.), Advanced Physical Geodesy. Karlsruhe, Germany, p. 500.

653 Okada, Y. (1985), Surface deformation due to shear and tensile faults in a halfspace, Bull. Seismol. Soc. Amer., 75, 1135-1154.

Palano M., Ferranti L., Monaco C., Mattia M., Aloisi M., Bruno V., Cannavò F., Siligato G. (2012), GPS velocity and strain fields in Sicily and southern Calabria, Italy: Updated geodetic constraints on tectonic block interaction in the central Mediterranean. Journal of Geophysical Research, Solid Earth, 117, B07401, doi:10.1029/2012jb009254.

Palano M. (2016), Episodic slow slip events and seaward flank motion at Mt. Etna volcano (Italy). Journal of Volcanology and Geothermal Research, 324, 8-14, doi:10.1016/j.jvolgeores.2016.05.010.

662 Pascal, K.; Neuberg, J.; Rivalta, E. (2014), On precisely modelling surface deformation due to 663 interacting magma chambers and dykes. Geophys. J. Int., 196, 253-278, doi: 10.1093/gji/ggt343.

Patanè, D., Aiuppa, A. Aloisi, M., Behncke, B., Cannata, A., Coltelli, M., Di Grazia, G., Gambino, S., Gurrieri, S., Mattia, M., Salerno, G. (2013), Insights into magma and fluid transfer at Mount Etna by a multiparametric approach: A model of the events leading to

Polcari, M., Fernández, J., Albano, M., Bignani, C., Palana, M., Stramondo, S. (2017), An improved data integration algorithm to constrain the 3D displacement field induced by fast deformation phenomena tested on the Napa Valley earthquake. Computers and Geosciences 109, 206-215. of Geophysical Research 88(B12), 1983, 10647-10652). 
677 Rymer, H and Williams-Jones, G. (2000), Volcanic eruption prediction: Magma chamber physics from gravity and deformation measurements. Geophys. Res. Lett., 27, 16, 23892392.

Samsonov, S., and N. d'Oreye (2012), Multidimensional time series analysis of ground deformation from multiple InSAR data sets applied to Virunga volcanic province, Geophys. J. Int., 191, 1095-1108, doi:10.1111/j.1365-246X.2012.05669.x.

Samsonov, S. V., K. F. Tiampo, A. G. Camacho, J. Fernández, and P. J. González (2014), Spatiotemporal analysis and interpretation of 1993-2013 ground deformation at Campi Flegrei, Italy, observed by advanced DInSAR, Geophys. Res. Lett., 41, doi:10.1002/2014GL060595.

Segall, P. (2010), Earthquake and Volcano Deformation. Princeton University Press, Princeton and Oxford (432 pp., ISBN 978-0-691-13302-7).

Siniscalchi, A., S. Tripaldi, M. Neri, M. Balasco, G. Romano, J. Ruch, and D. Schiavone (2012), Flank instability structure of Mt. Etna inferred by a magnetotelluric survey, J. Geophys. Res., 117, B03216, doi:10.1029/2011JB008657.

Tiampo, K.F., González P.J., Samsonov S. (2013), Results for aseismic creep on the Hayward fault using polarization persistent scatterer InSAR. Earth Planet. Sc. Lett., 367, 157165.

Wegmuller, U. \& Werner, C. (1997), GAMMA SAR processor and interferometry software. In The 3rd ERS symposium on space at the service of our environment, Florence, Italy.

Williams, C. \& Wadge, G. (1998), The effects of topography on magma chamber deformation models: Application to Mt. Etna and Radar Interferometry, Geophys. Res. Lett., 25, 1549-1552, doi: 0094-8534/98/98GL-011365. 


\section{Figures}

703

704

705

706

707

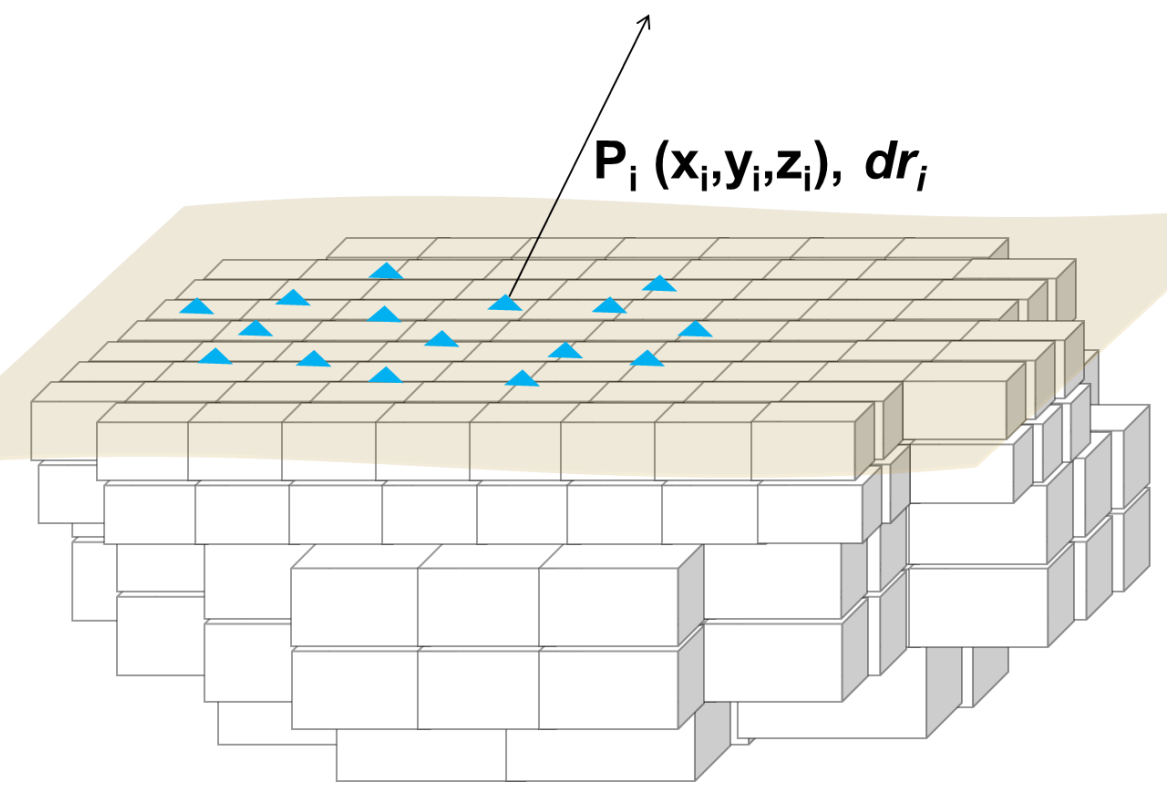

708

Figure 1. Partition of the subsurface volume below the survey into a $3 D$ grid of thousands of 709 small right prisms. Blue triangles correspond to data points (terrestrial stations or pixels) $P_{i}$ with coordinates $\left(x_{i}, y_{i}, z_{i}\right)$ and observed deformation vector $\boldsymbol{d r}_{i}$. 


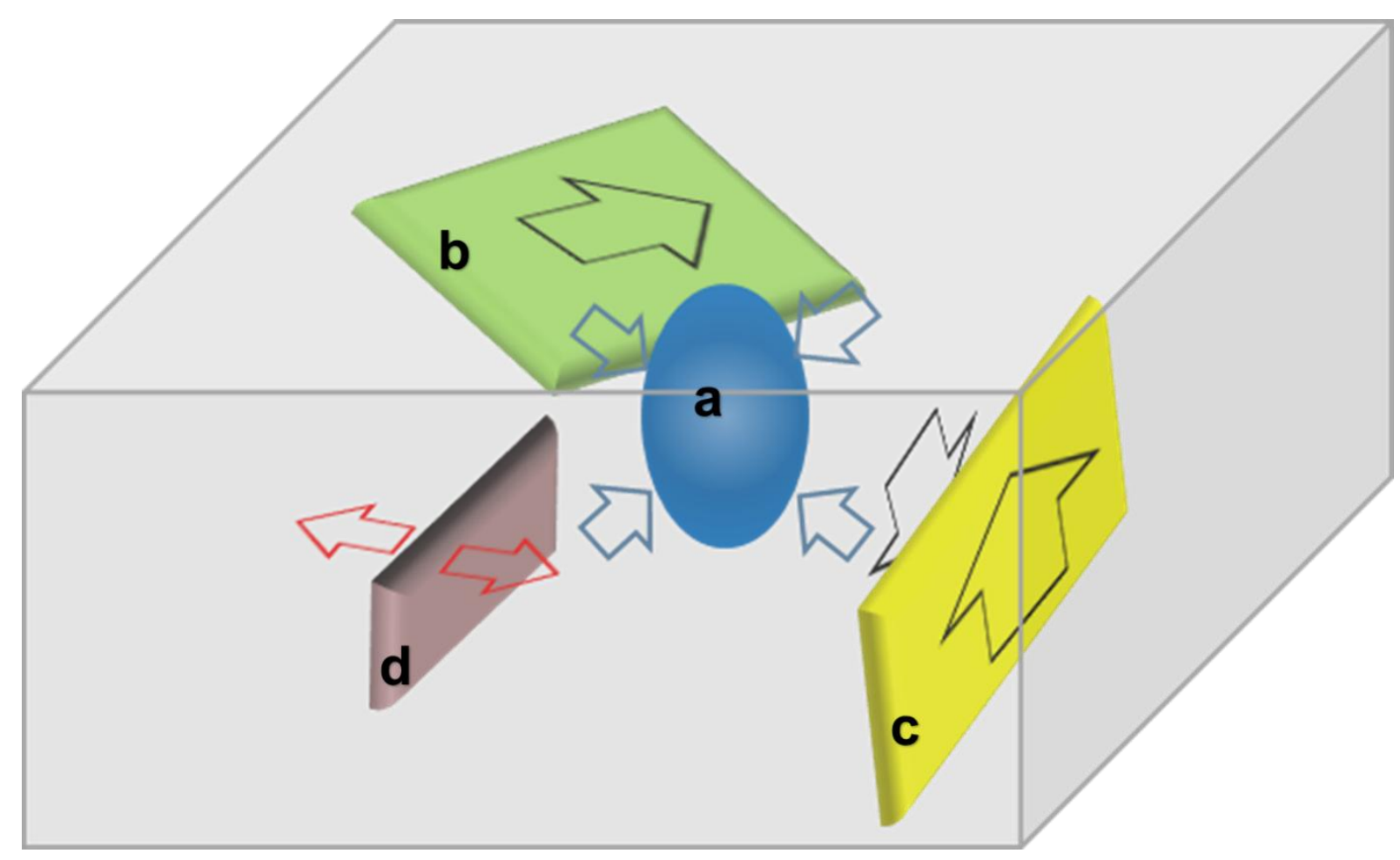

Figure 2. Synthetic source structure composed by: (a) a vertical ellipsoid with a

722 decreasing pressure (blue), (b) a sub-horizontal strike slip fault (green), (c) a nearly vertical 723 dip slip fault (yellow), and (d) a nearly vertical tensile fault (brown). See text for details on the sources characteristics. 

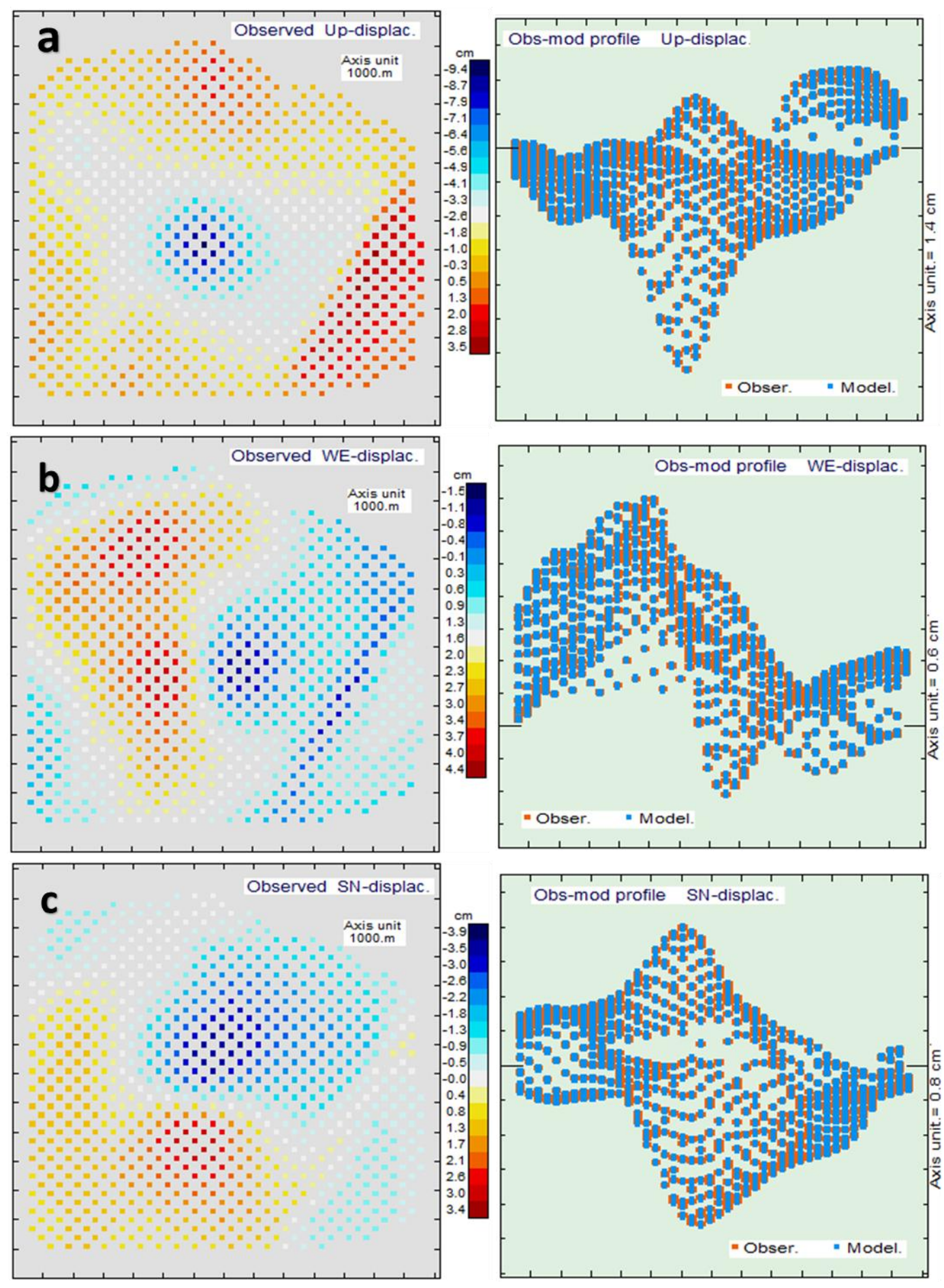

Figure 3. Left panels show the simulated deformation values corresponding to the active structures shown in figure 2 for the 800 data points used for inversion. (a) Up component. (b)

729 EW component. (c) NS component. Right panels show the data fit corresponding to the inverse model for each component. Observed data are plotted in orange, modelled in blue. 


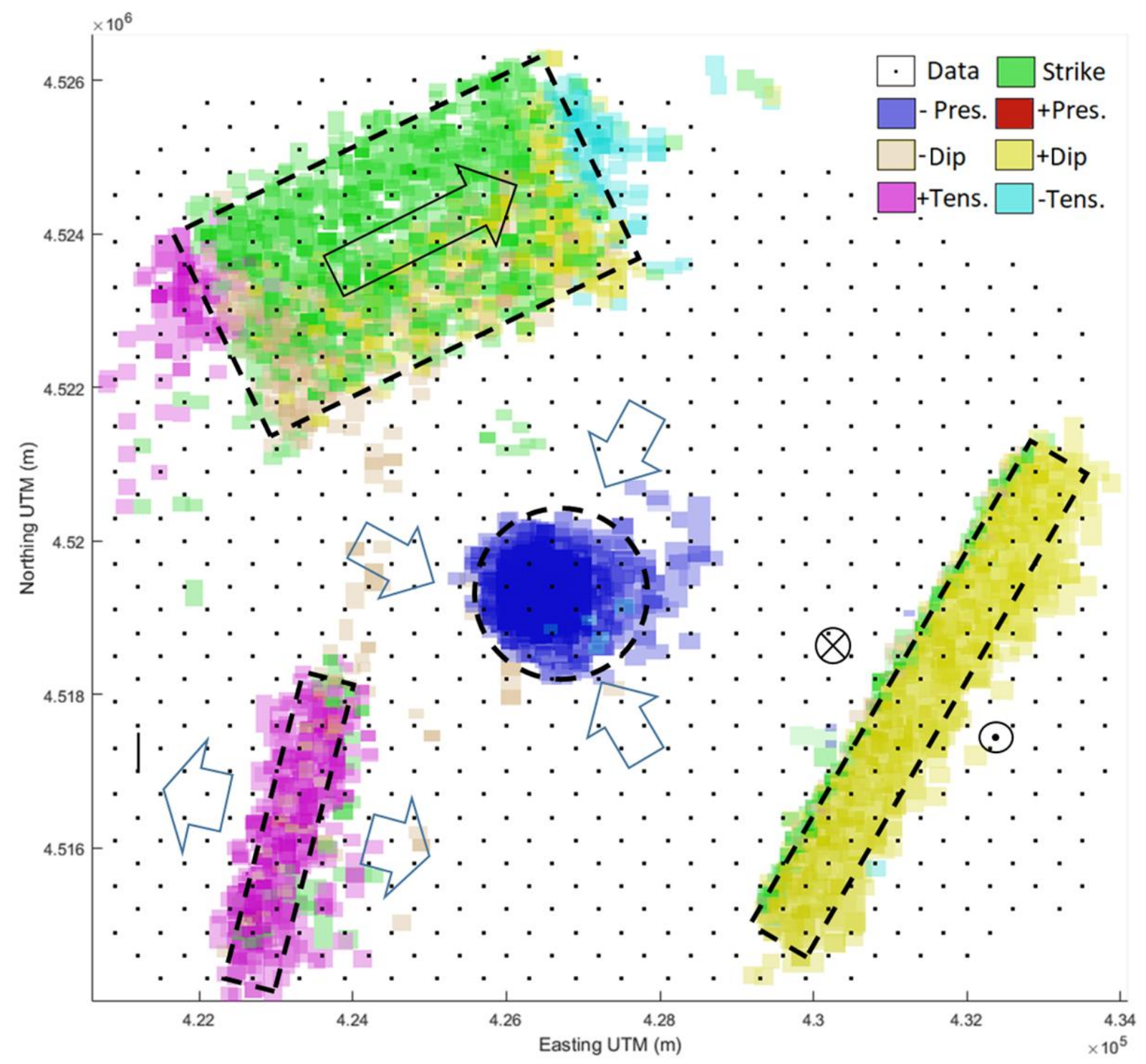

Figure 4. Horizontal view from the top of the resulting source structures, described as aggregation of different elemental source cells, and obtained by application of the inverse approach. Dots indicate data sites, and discontinue lines the location of the synthetic bodies. 


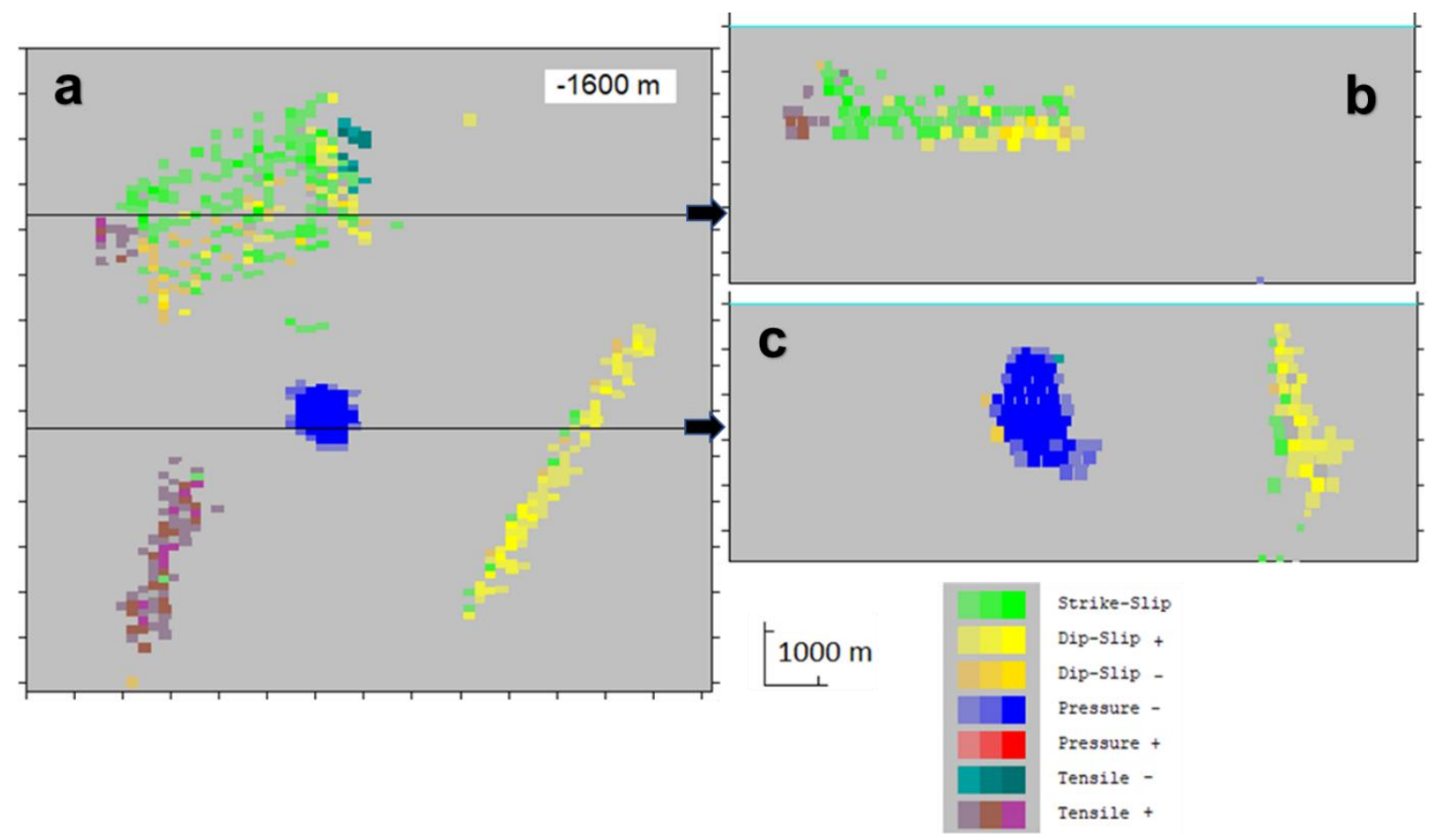

$744 \quad$ Figure 5. Inverse 3D source model as aggregation of elemental cells. (a) Horizontal sections at $1500 \mathrm{~m}$ depth; (b) EW vertical profile across the strike structure (green cells); (c) EW

746 vertical profile across the low pressure structure (blue cells) and dip-slip structure (yellow 


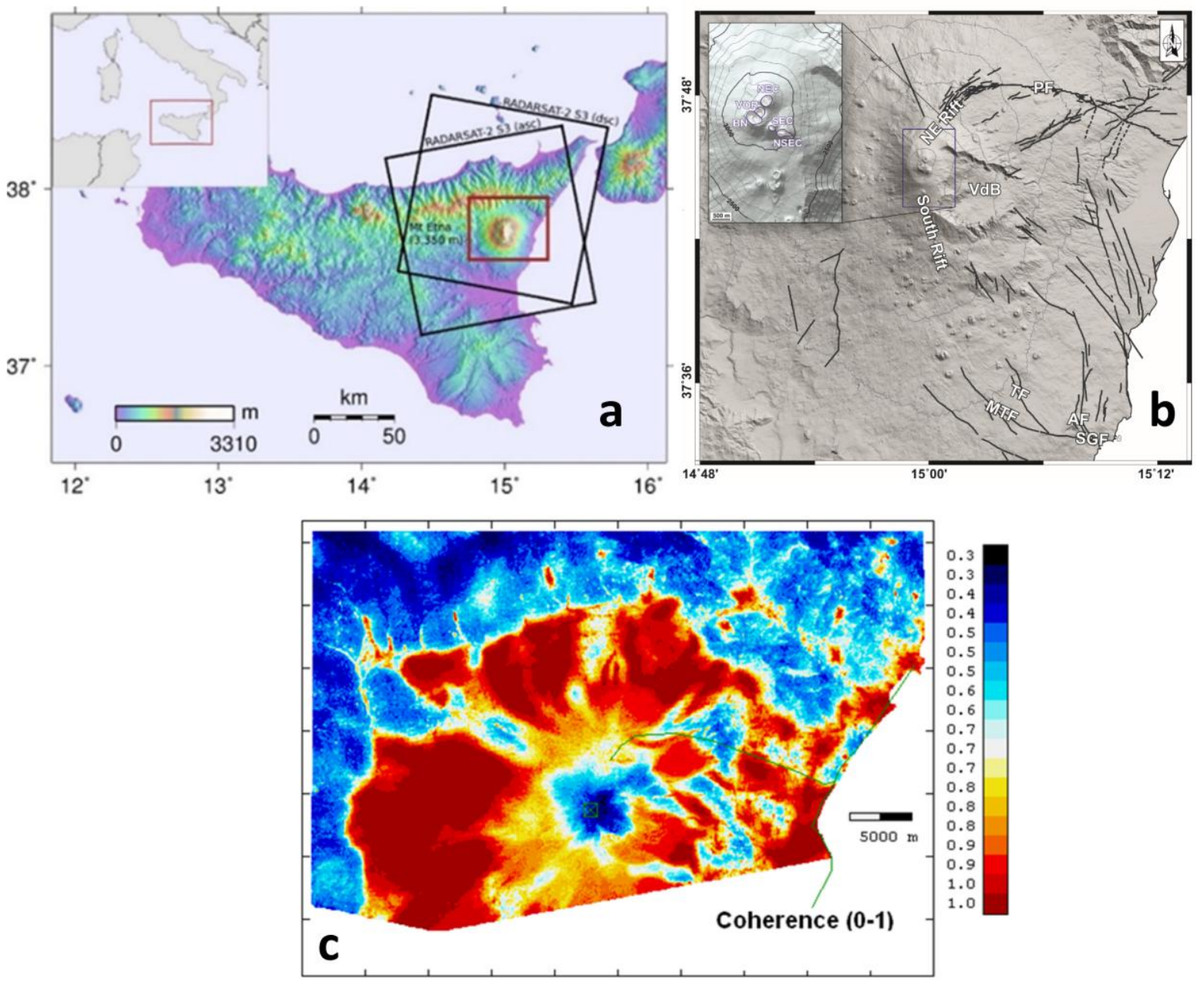

Figure 6. (a) Study area (outlined in an inner red square) and RADARSAT-2 frames outlined in black. (b) Simplified tectonic map of Mt. Etna. Abbreviations are as follows: PF, 754 Pernicana fault; AF, Acitrezza fault; TF, Trecastagni fault; MTF, Mascalucia-Tremestieri fault; VdB, Valle del Bove. Inset shows a zoom of the volcano summit (Bocca Nuova, BN;

756 Voragine, VOR; North-East Crater, NEC; South-East Crater, SEC; New South-East Crater, NSEC). (c) InSAR pixels for the period January 2009 - June 2013 at Mt. Etna. Colours correspond to coherence values. 

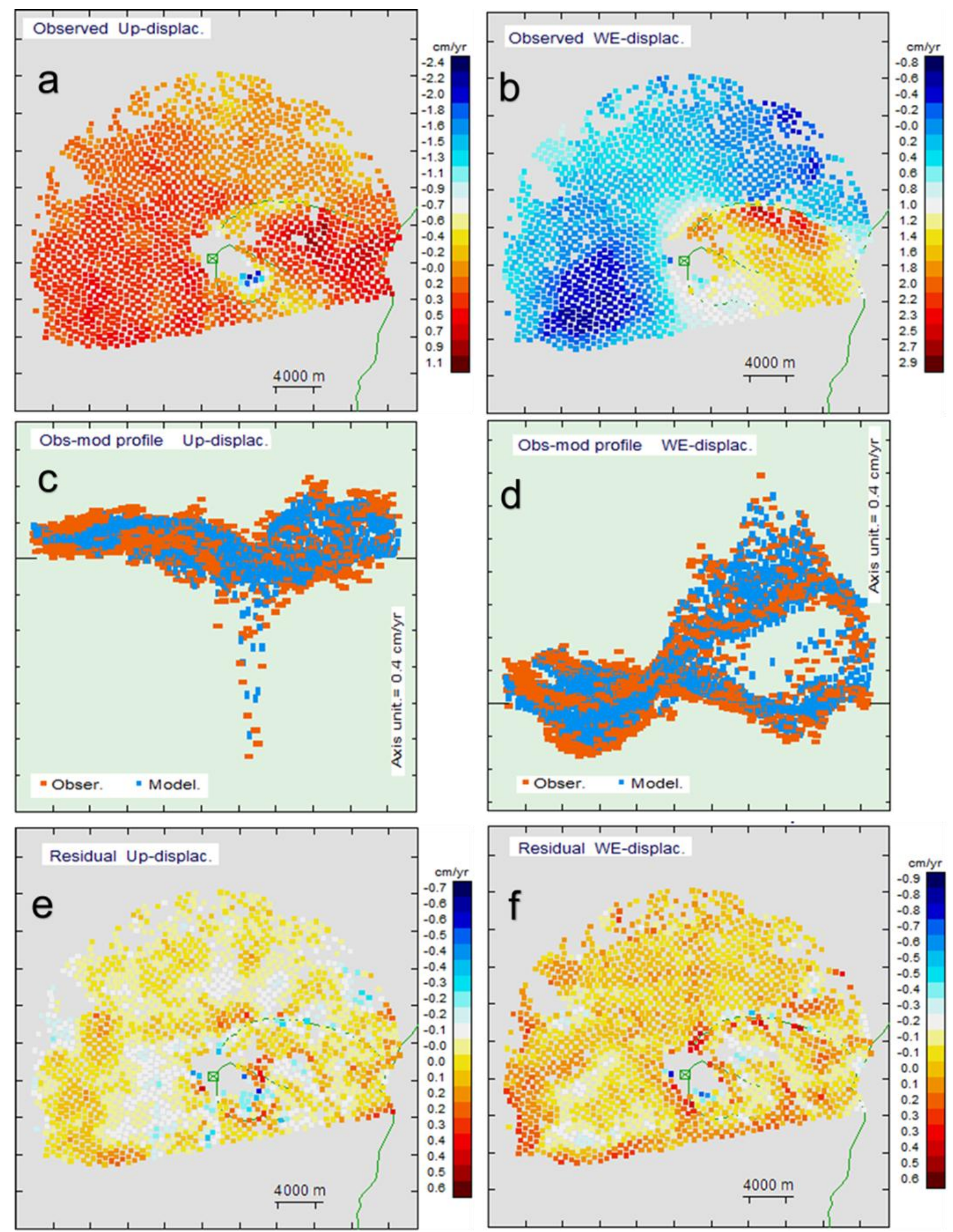

Figure 7. Observed displacement rate (cm/year): (a) Vertical and (b) EW component for the

1613 pixels selected from the total dataset (Figure 6). Comparison between observed and modelled values: (c) Vertical and (d) EW component. Final residuals corresponding to local 

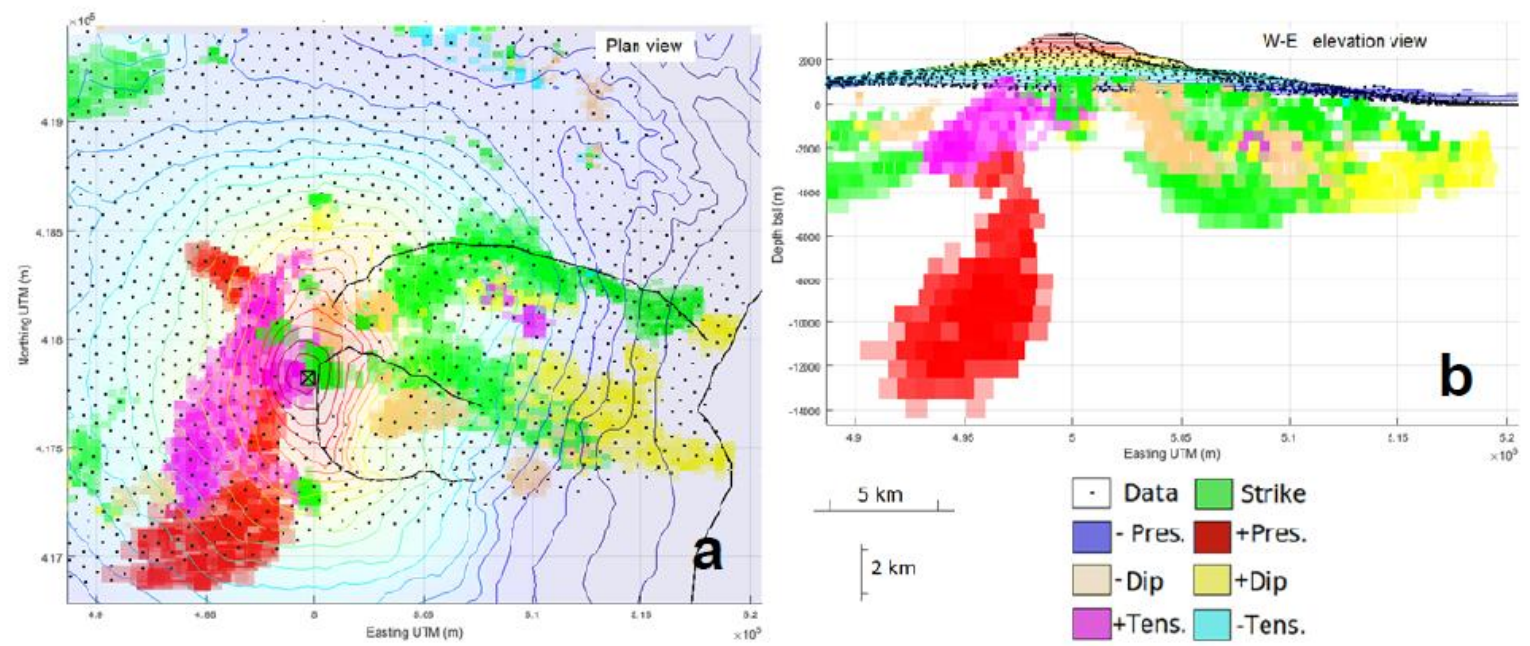

$770 \quad$ Figure 8. 3D inverse model described as aggregation of approximately 12,000 different

771 elemental cells ( $440 \mathrm{~m}$ on a side), and obtained by application of the inverse approach: (a)

772 Planar and (b) EW vertical views. Colours indicate the source nature of the cell. Black lines denotes the Permicana Fault, Valle del Bove limit and coast line (see Figure 6). 


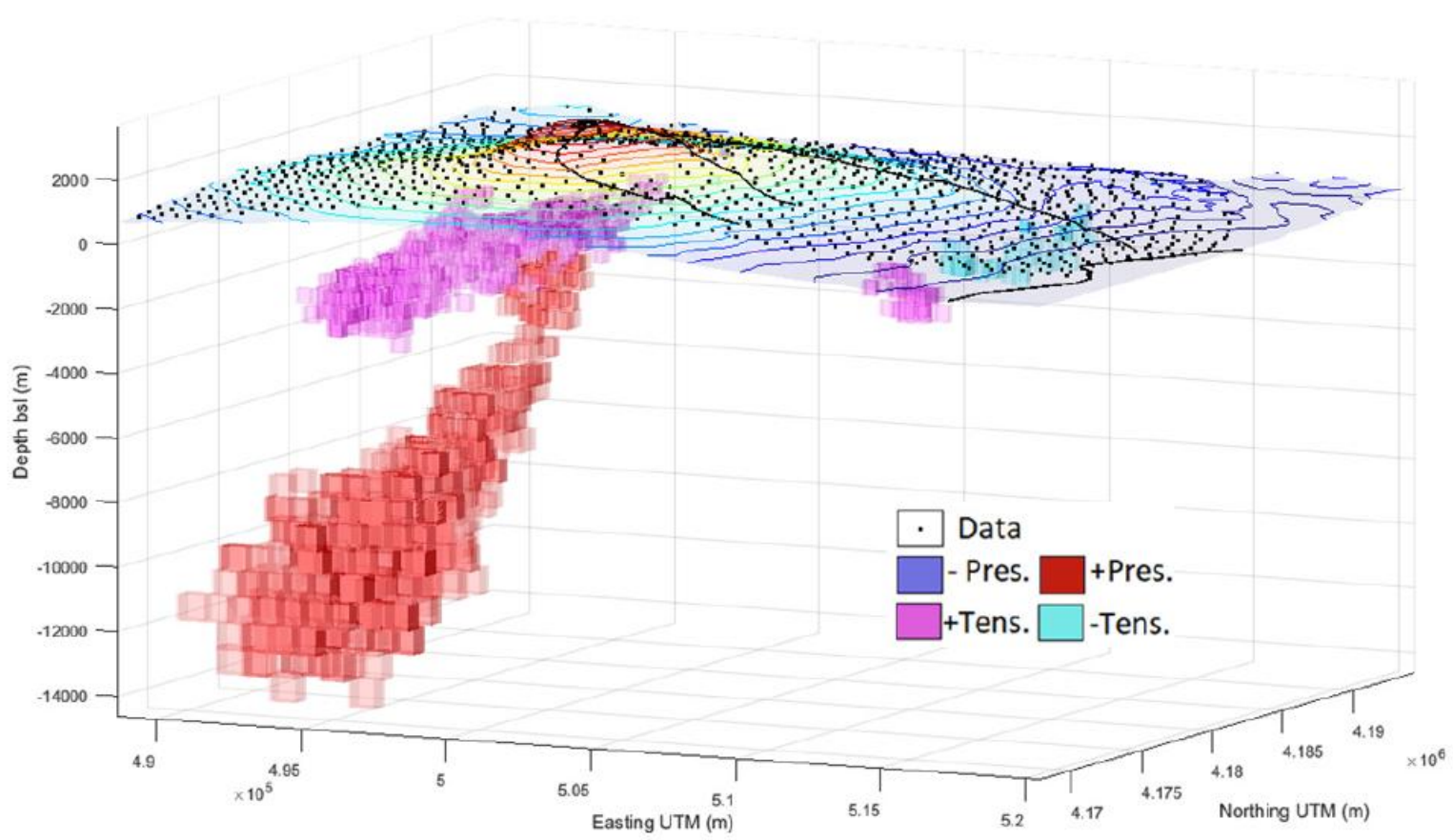

779 Figure 9. Perspective 3D view of those source elements in Figure 6 corresponding to the 780 plumbing system: increasing pressure cells (large deep reservoir with mean depth $\sim 11 \mathrm{~km} \mathrm{bsl}$, 781 SW of Etna, and shallow small reservoir with mean depth $3 \mathrm{~km}$ bsl. NW of Etna and along the 782 elongation of the deep reservoir), and expanding tensile cells (at levels $1 \mathrm{~km}$ and $2 \mathrm{~km} \mathrm{bsl,}$ 783 with elongated pattern SW-NW). Black lines correspond to Etna summit, Pernicana Fault and 784 Valle del Bove limit (see Figure 6). 

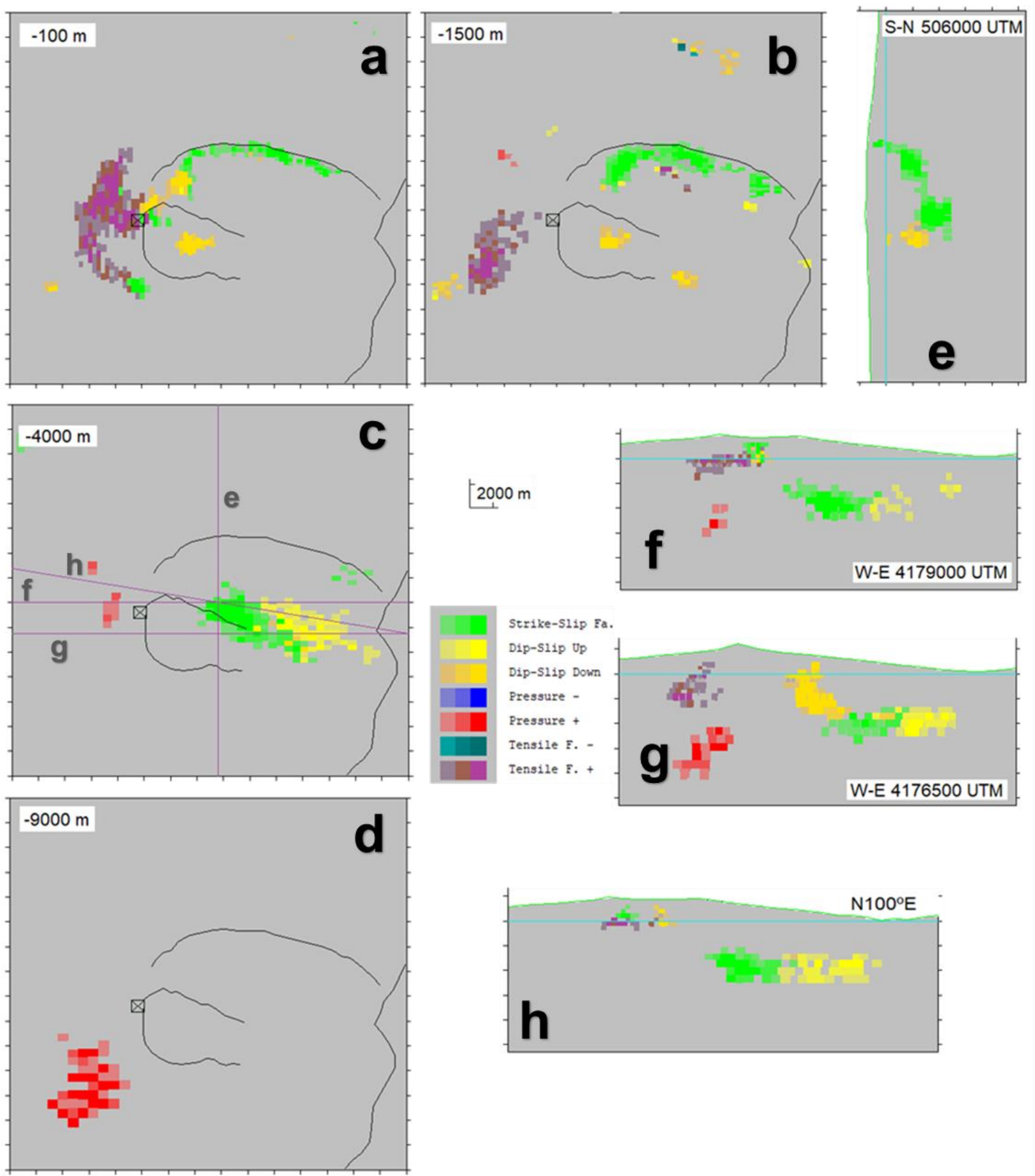

Figure 10. Some horizontal and vertical sections of the tensile structure (purple), strike-slip structure (green), dip-slip structure (yellow) and high pressure (red) from the inverse model. (a),(b),(c) and (d): Horizontal sections at depths 500, 1000, 4000 and $9000 \mathrm{~m} \mathrm{bsl}$. (e) SN vertical section across the strike structure. $(\boldsymbol{f})$ and $(\mathrm{g})$ : WE vertical sections. (h) Vertical section with azimuth $100^{\circ}$. Green lines correspond to Etna summit, Pernicana Fault and Valle del Bove. Location of vertical sections $(\boldsymbol{e})$ to $(\boldsymbol{h})$ are indicated by lines in panel $(\boldsymbol{c})$. 


\section{Methodology}

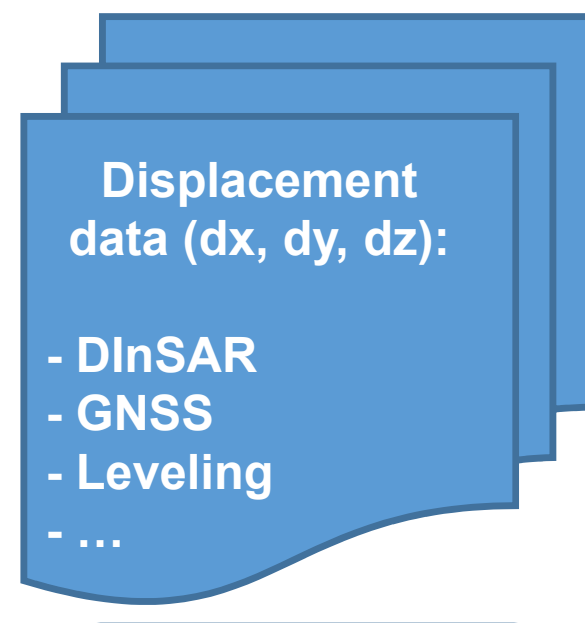

3D grid of (empty) cells to be filled by elementary sources.

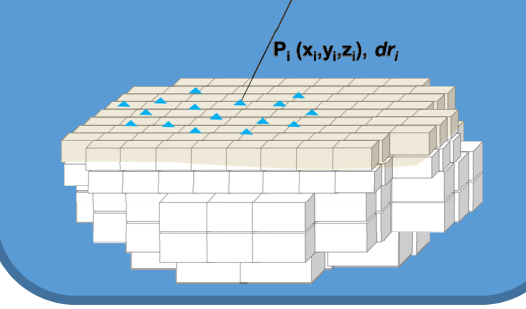

Elastic parameters.

Dislocations and pressure anomalies.

\section{Model Equations}

$\boldsymbol{d r}^{\boldsymbol{c}}=\sum_{\Phi_{P}}\left(\begin{array}{l}u_{x} \\ u_{y} \\ u_{z}\end{array}\right)+\sum_{\left(\Phi_{S, D}, \Phi\right.}\left(\begin{array}{l}u_{x} \\ u_{y} \\ u_{z}\end{array}\right)$ $d r_{j}^{c}=\sum_{i \epsilon \Phi_{P}} \Delta V_{i} \Delta \rho_{i} f_{p}\left(r_{i j}\right)+\sum_{i \in \Phi_{S}} \Delta S_{i} \Delta \sigma_{i} f_{S}\left(r_{i j}, \alpha_{i}, \delta_{i}\right)+\sum_{i \in \Phi_{D}} \Delta S_{i} \Delta \sigma_{i} f_{D}\left(r_{i j}, \alpha_{i}, \delta_{i}\right)+\sum_{\substack{i \in \Phi_{T} \\ j=1, \ldots, n}} \Delta S_{i} \Delta \sigma_{i} f_{T}\left(r_{i j}, \alpha_{i}, \delta_{i}\right)$

\section{Minimization condition}

$$
\boldsymbol{\varepsilon}^{T} \mathbf{Q}_{\mathbf{D}}^{-1} \boldsymbol{\varepsilon}=\min
$$

\section{Smoothing conditions}

$$
\mathbf{m}^{T} \mathbf{Q}_{M}^{-1} \mathbf{m}=\min
$$

\section{Mixed minimization equation}

$$
\boldsymbol{\varepsilon}^{T} \mathbf{Q}_{D}^{-1} \boldsymbol{\varepsilon}+\gamma \mathbf{m}^{T} \mathbf{Q}_{M}^{-1} \mathbf{m}=\min
$$

\section{D Anomalous Sources}

\section{Extended 3D model} for structures of anomalous pressure and dislocations defined as aggregation of cells filled with elementary sources.

\section{Growth process (scale factor)}

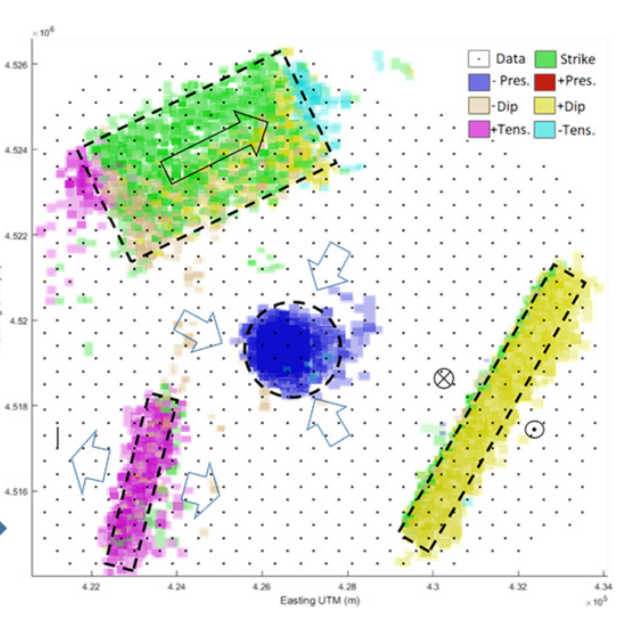


Figure 1
Click here to download Figure: Figure1.pdf

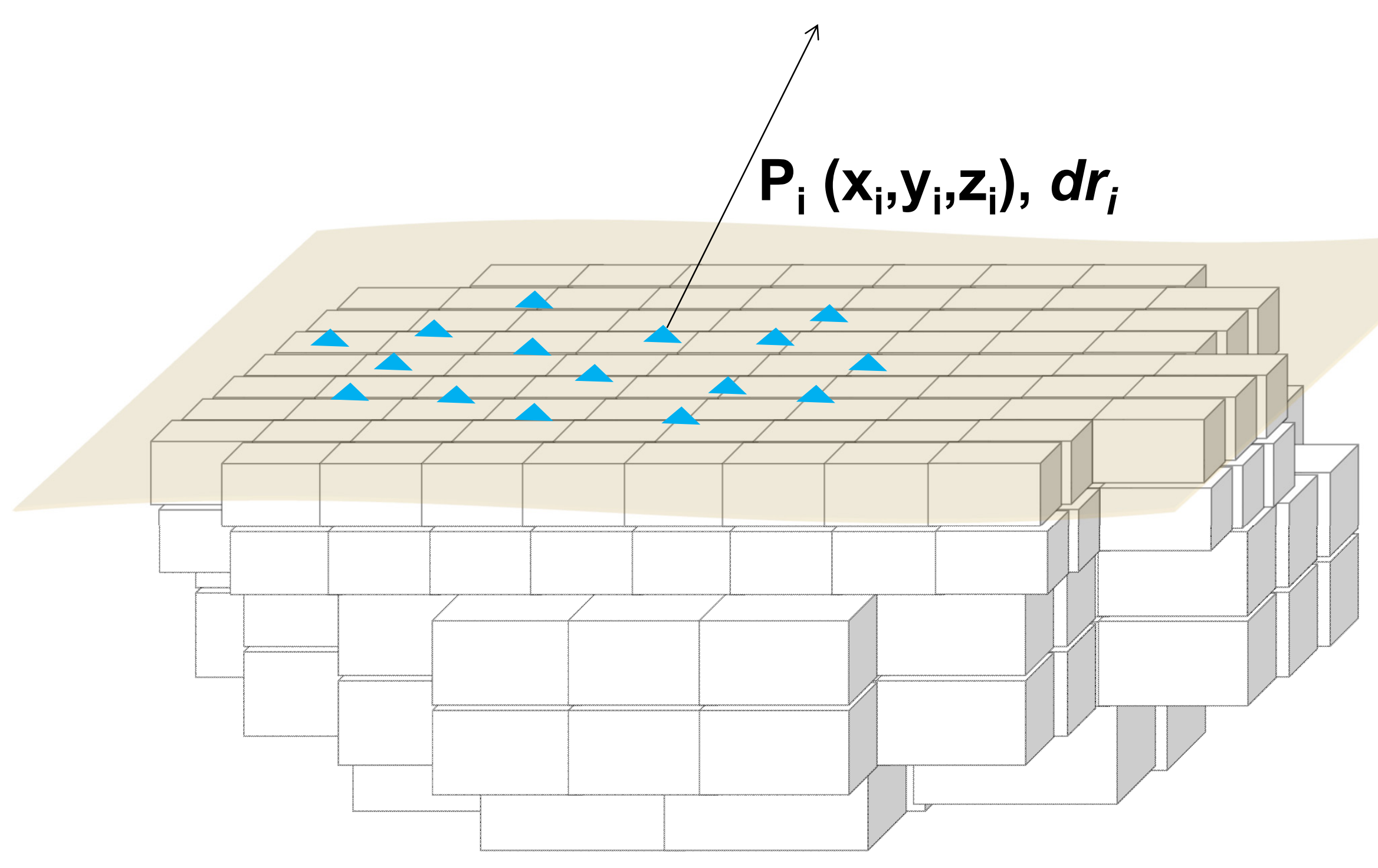

Click here to download Figure: Figure1.pdf 


\section{Figure 2}

Click here to download Figure: Figure2.pdf

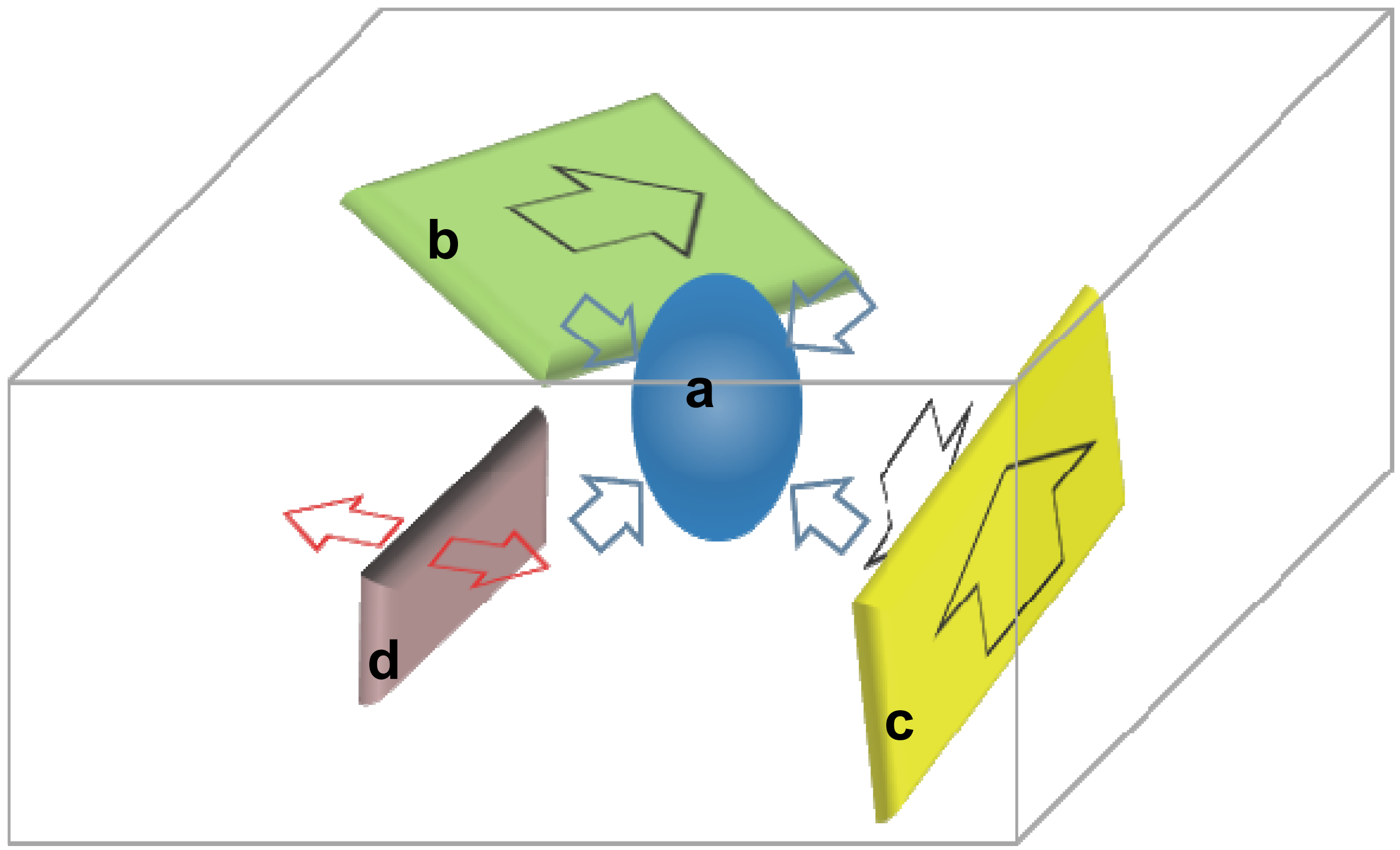




\section{Figure 3}

Click here to download Figure: Figure3.pdf
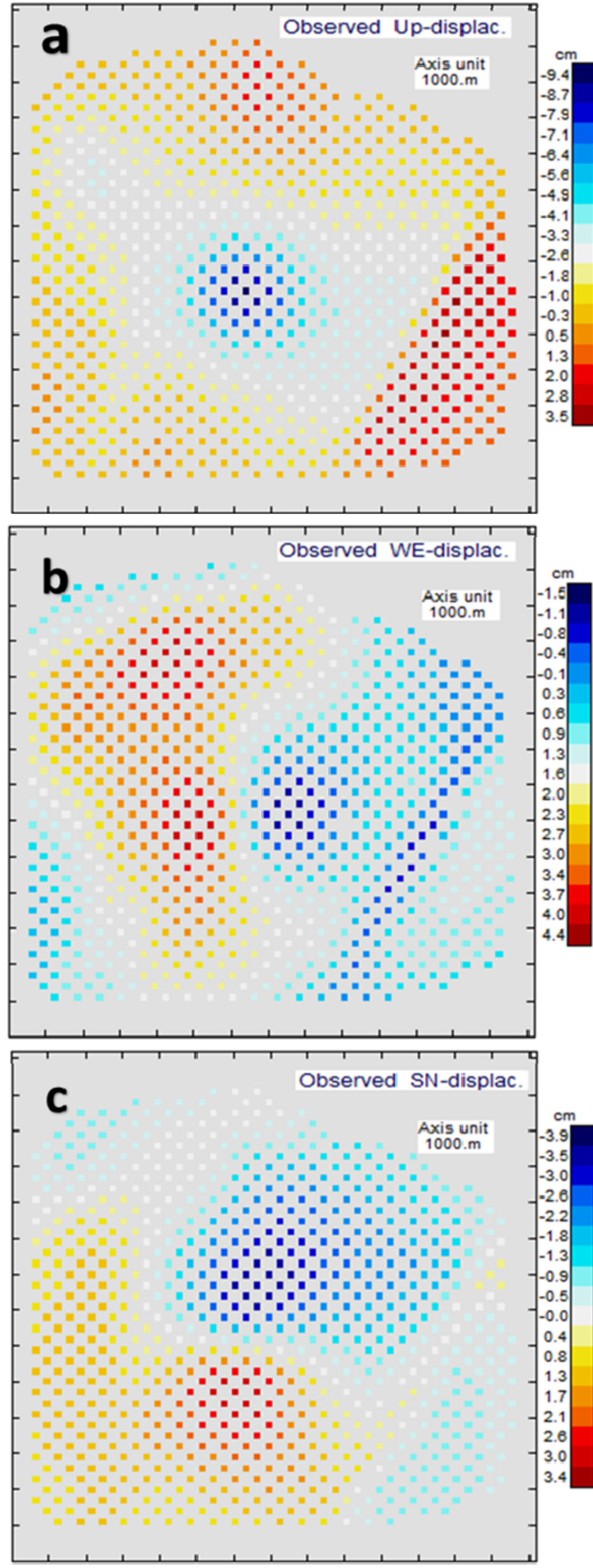
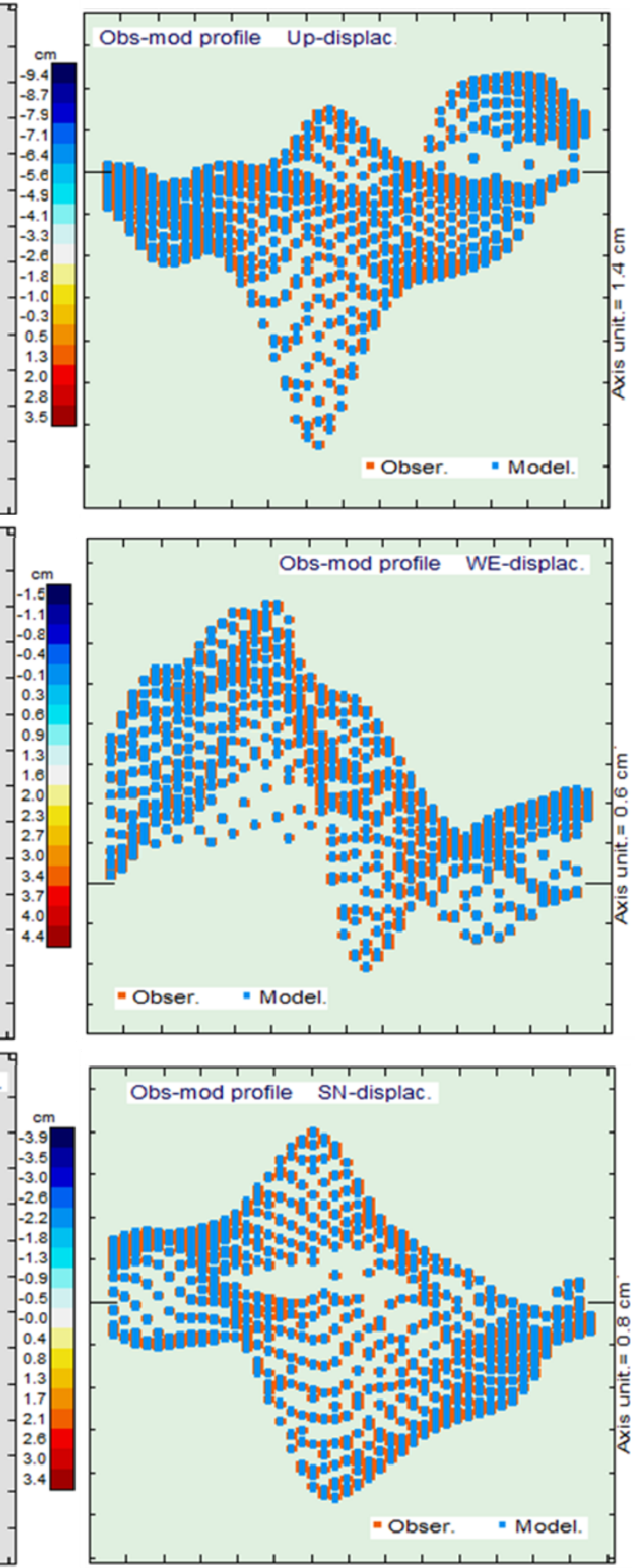

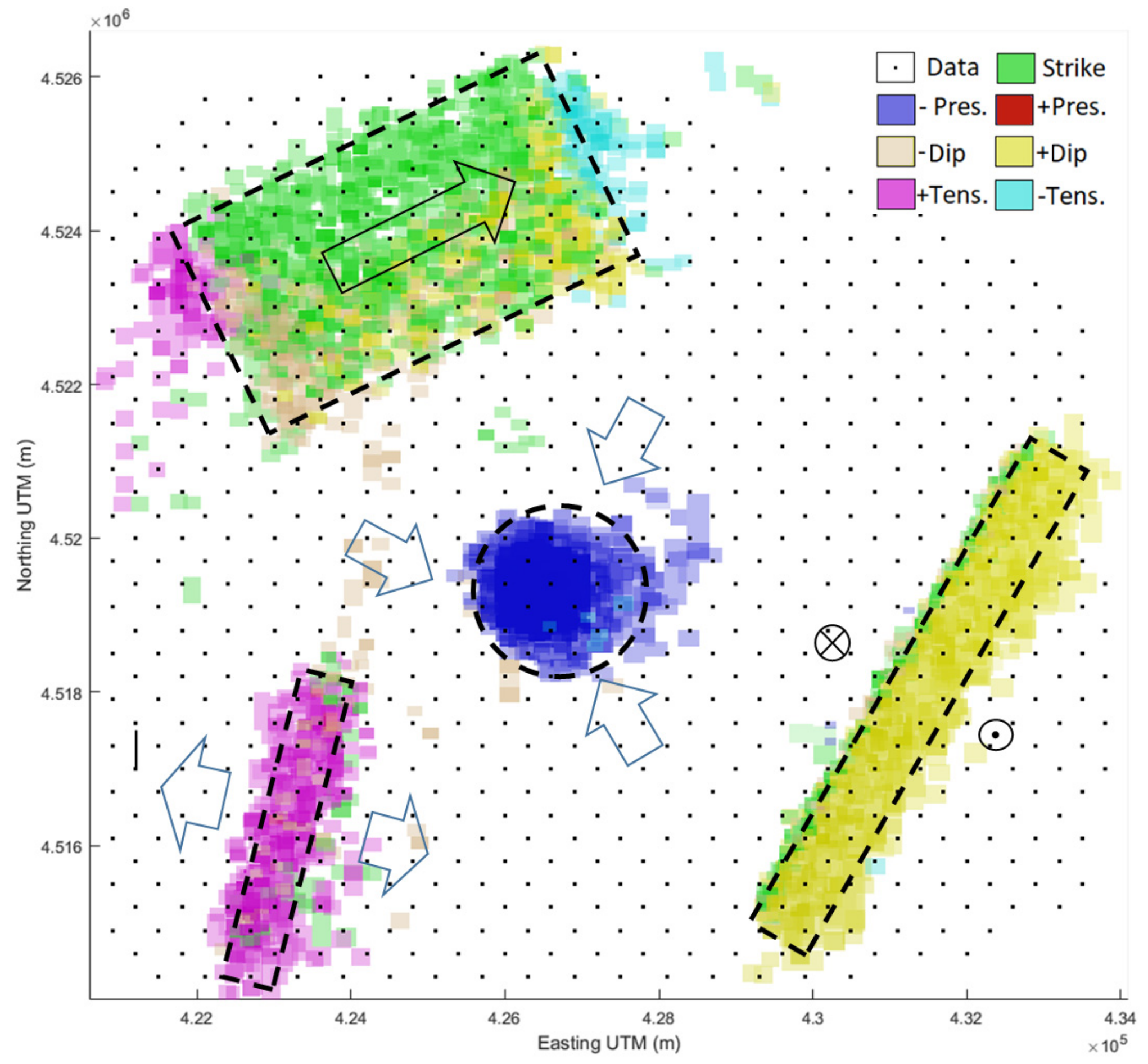


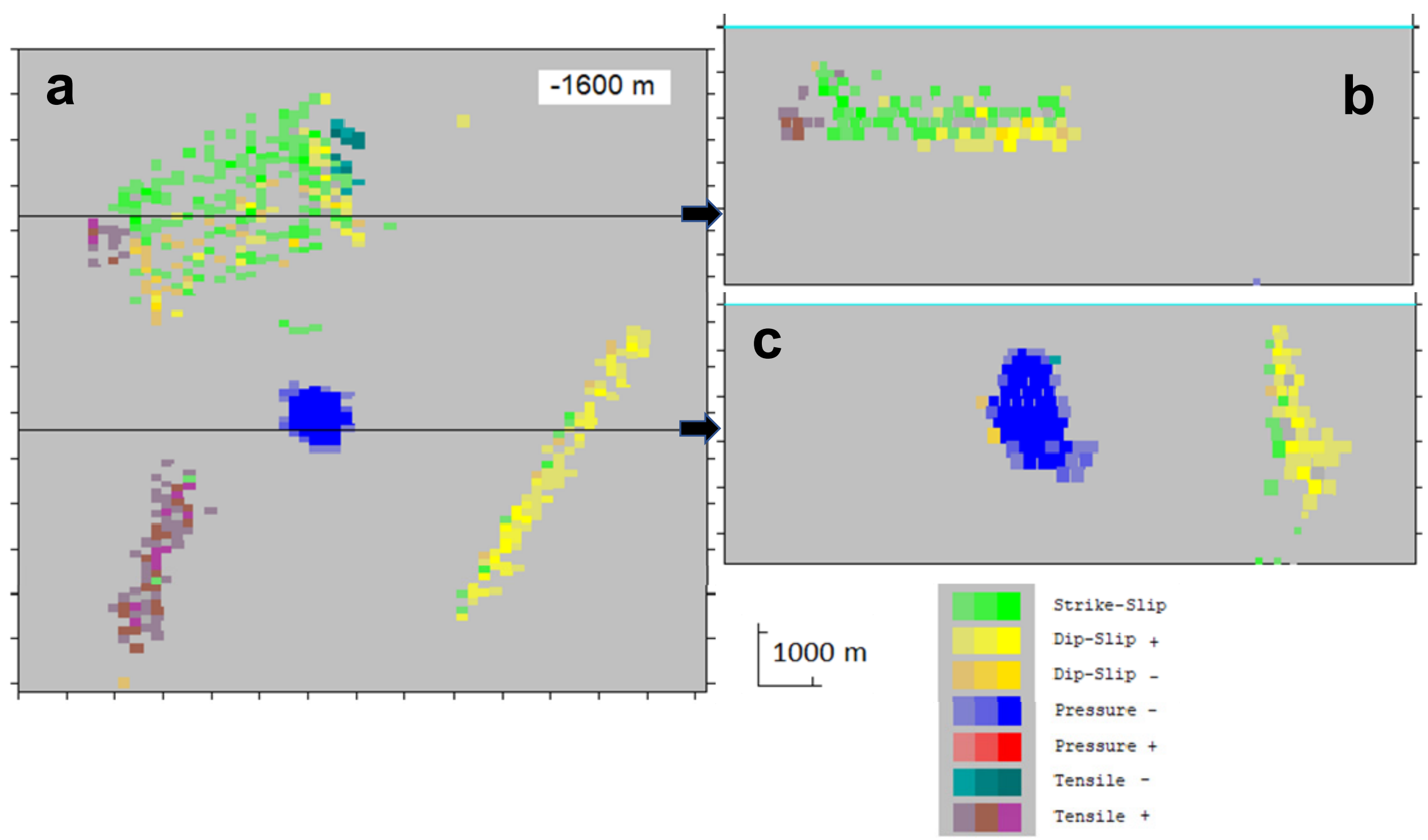


Figure 6

Click here to download Figure: Figure6.pdf
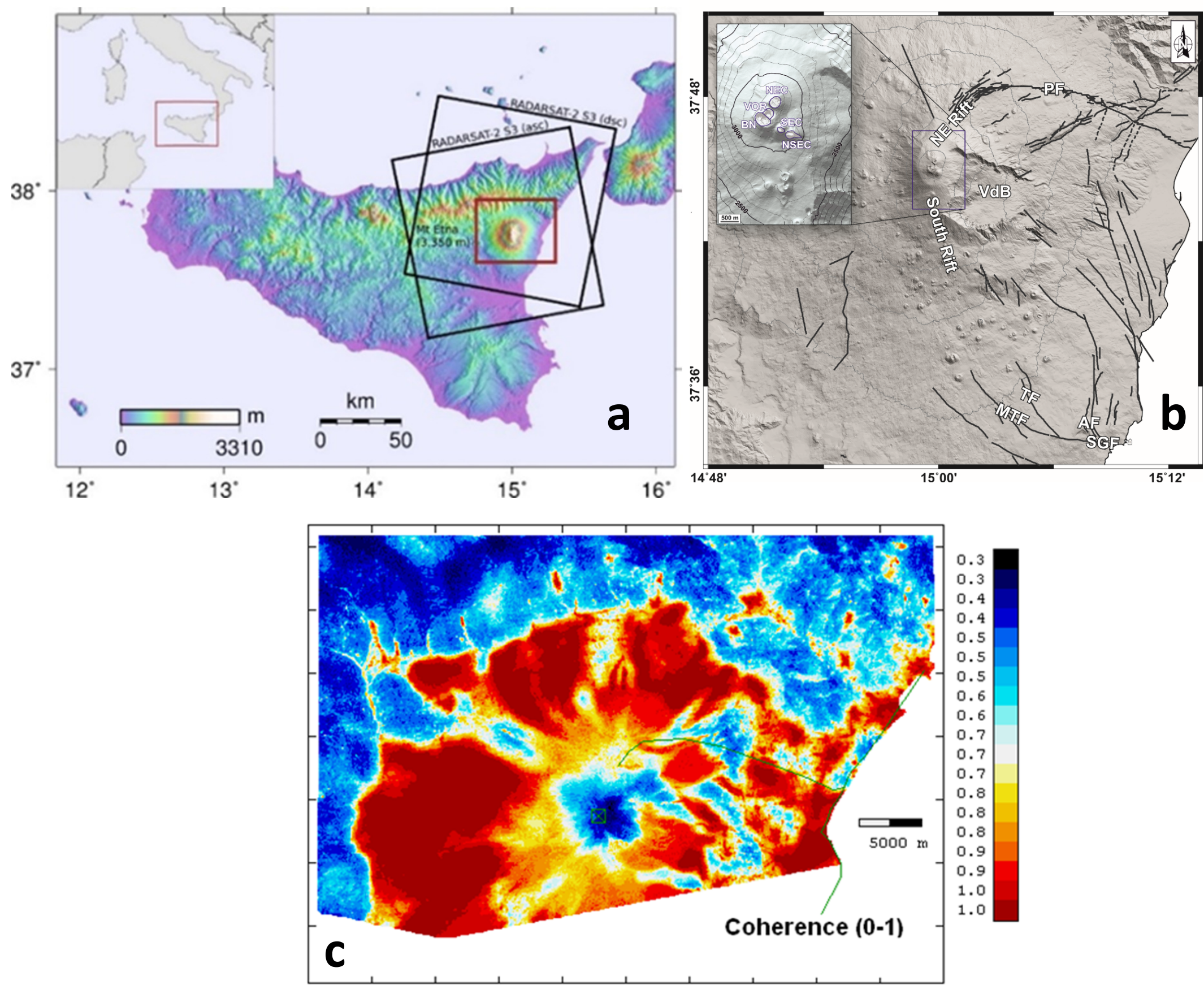

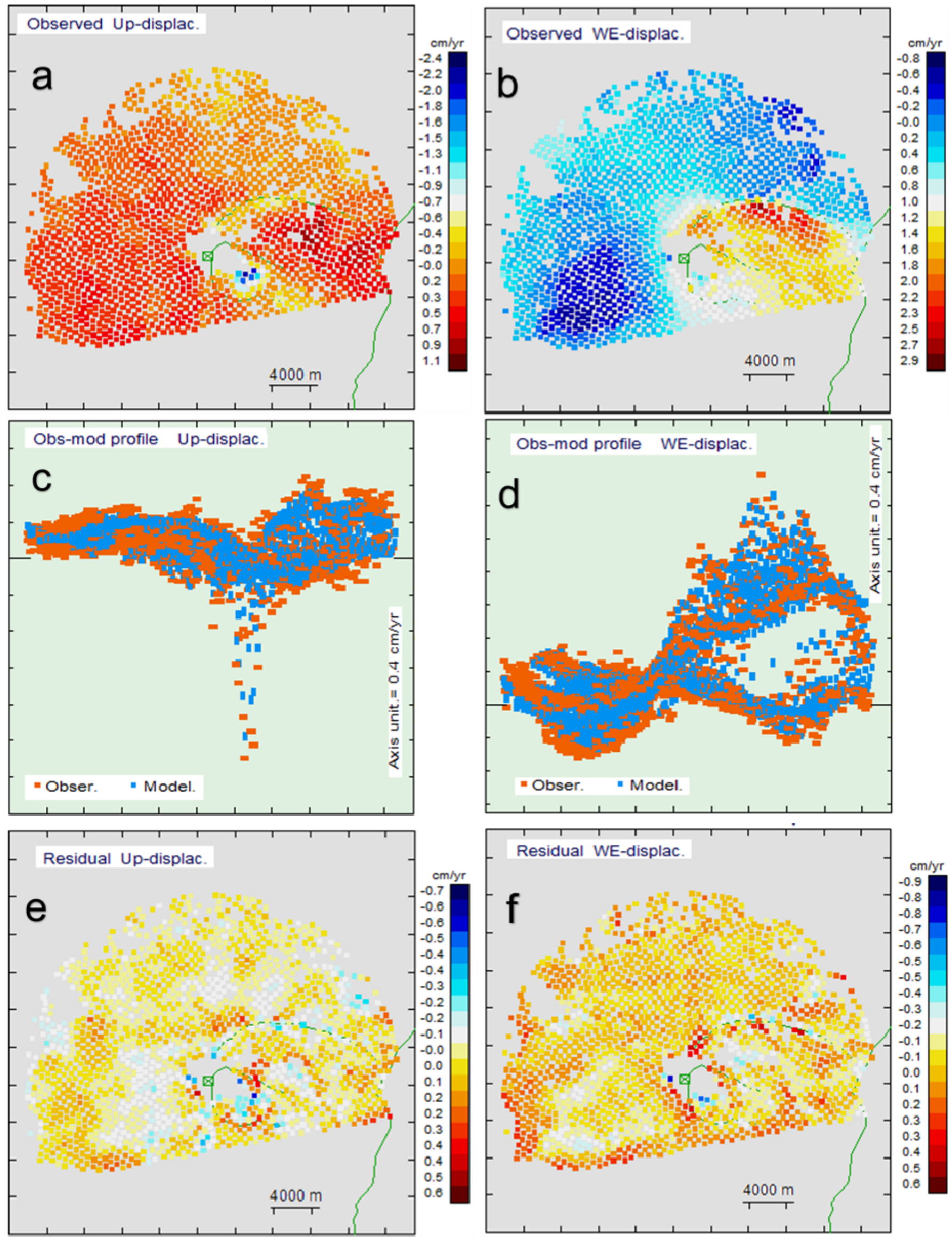


\section{Figure 8}

Click here to download Figure: Figure8.pdf
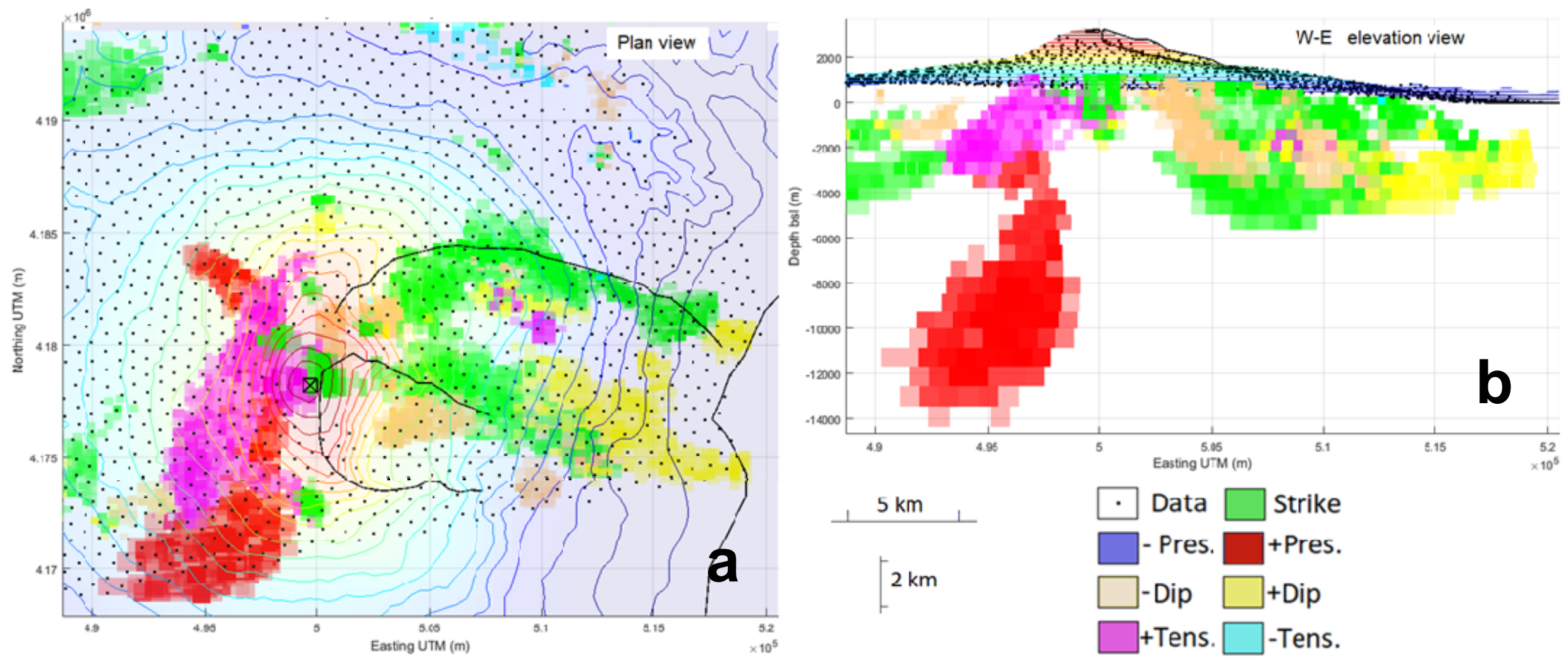
Click here to download Figure: Figure9.pdf

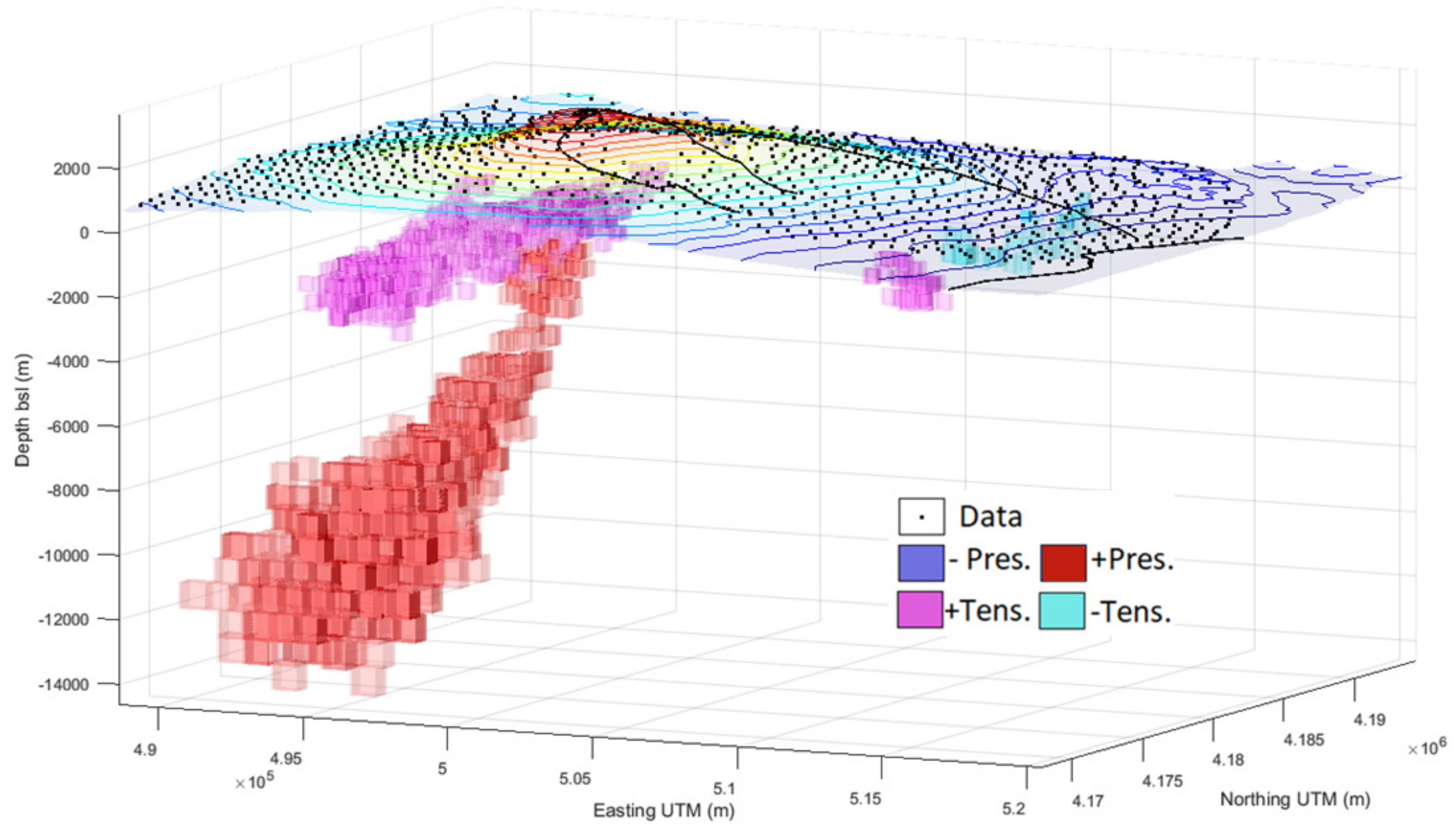



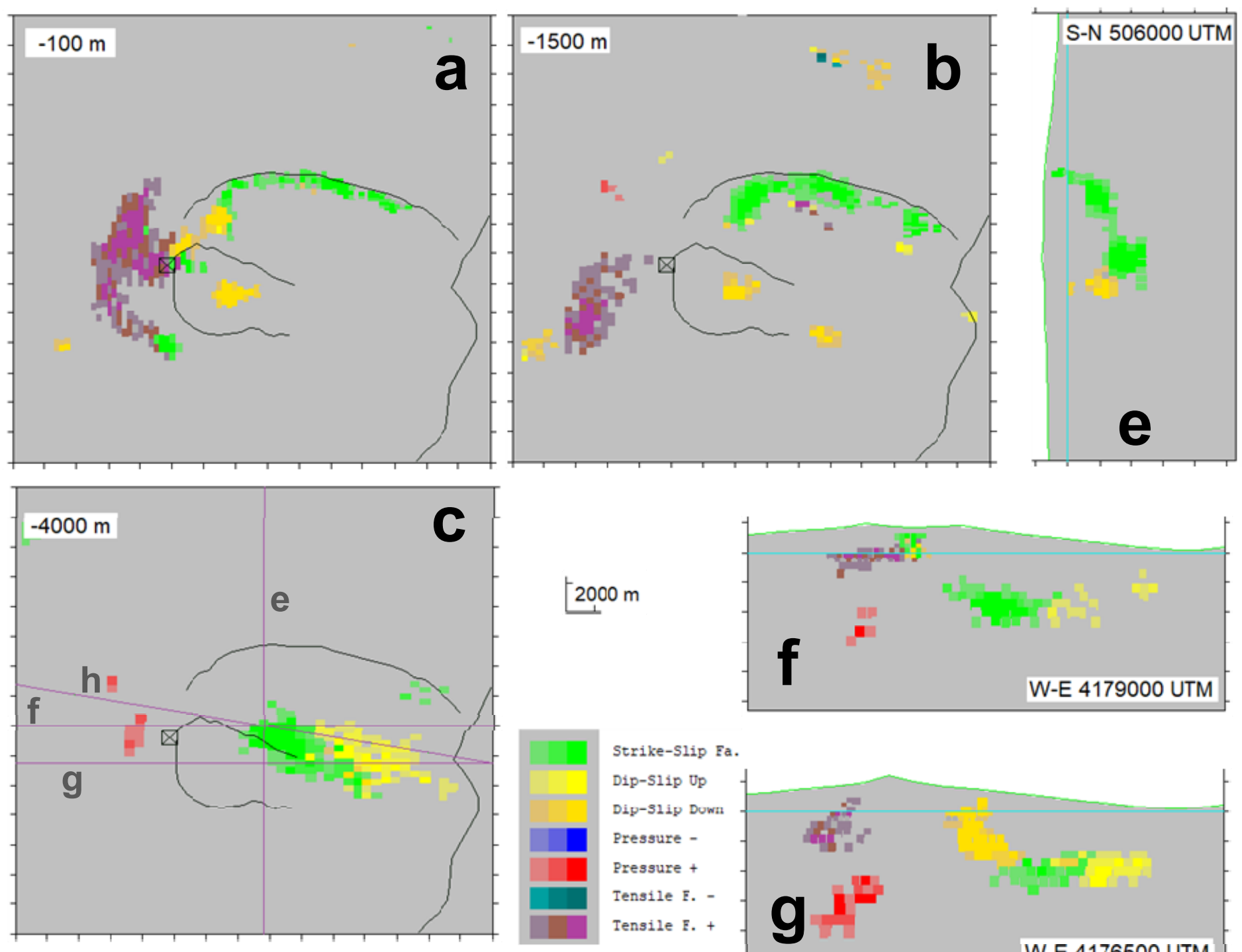

$2000 \mathrm{~m}$

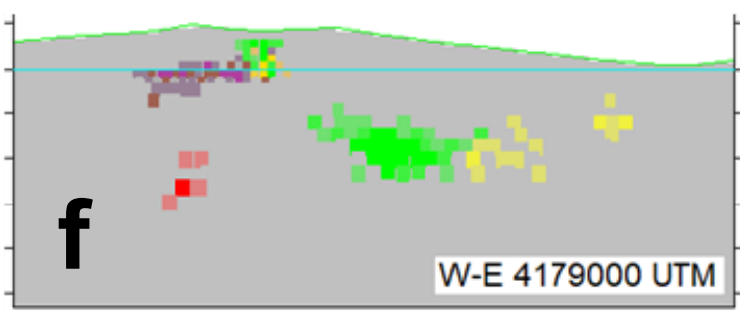

Strike-Slip Fa. Dip-Slip Up Dip-s1ip Duwa Pressure Pressure + Tensile F. Tensile F. +
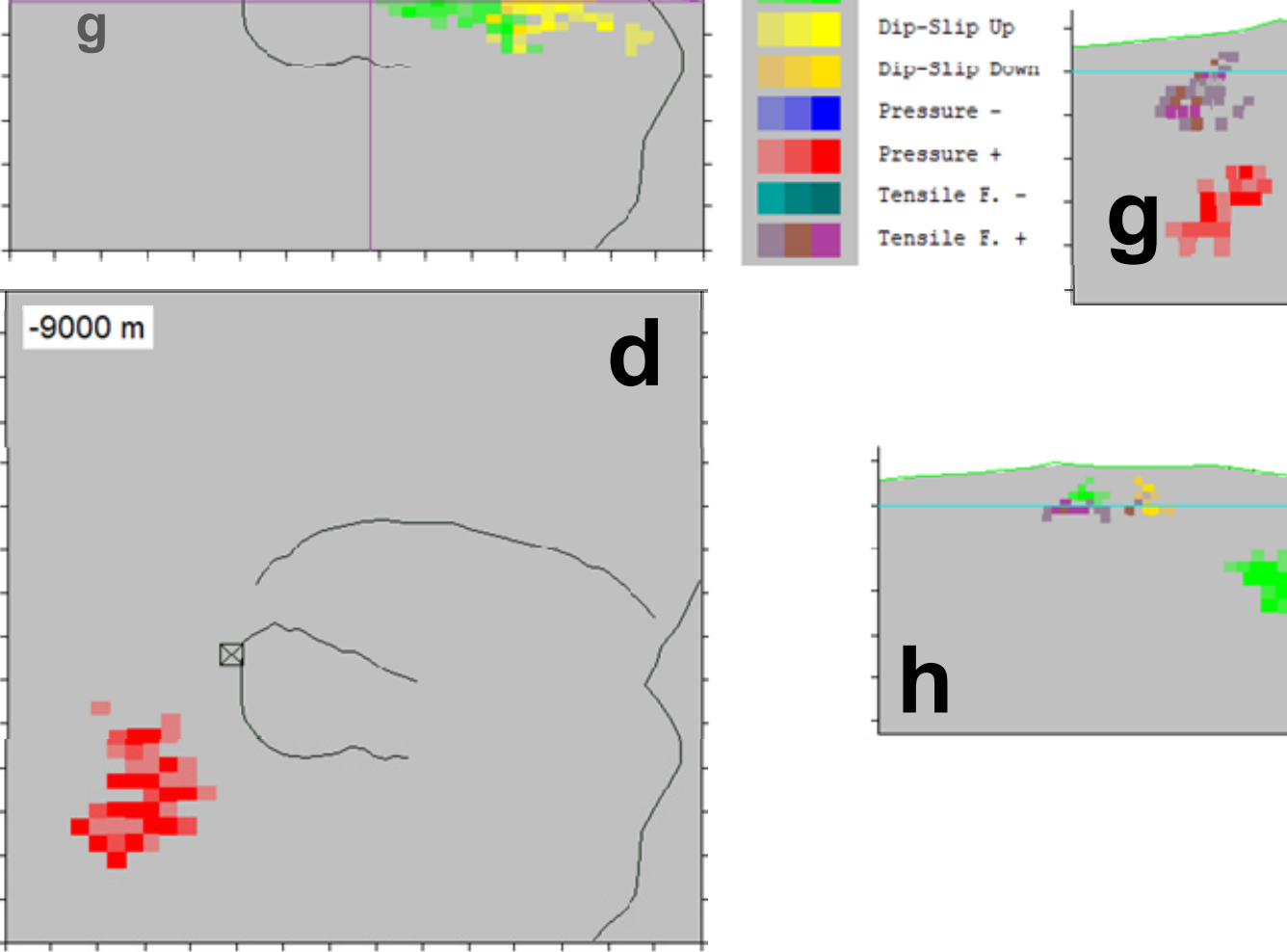

W-E 4176500 UTM

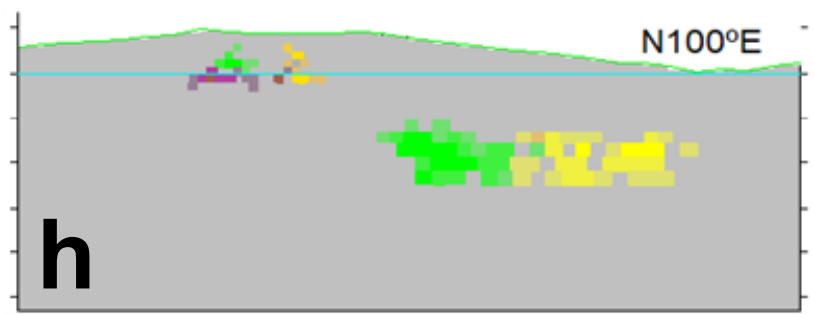



Supplementary material for online publication only
Click here to download Supplementary material for

Supplementary material for online publication only
Click here to download Supplementary material for online publication only: Camacho_et_al_2020_EPSL_SM_rev.pdf click here to download Supplementary material for (n)

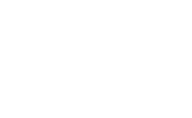




\section{Declaration of interests}

$\bigotimes$ The authors declare that they have no known competing financial interests or personal relationships that could have appeared to influence the work reported in this paper.

$\square$ The authors declare the following financial interests/personal relationships which may be considered as potential competing interests:

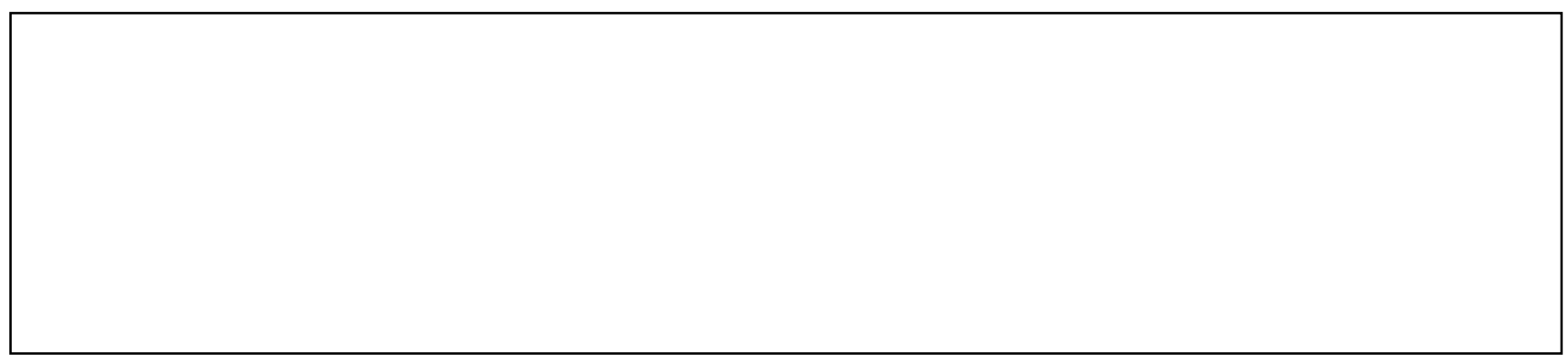




\section{CRediT author statement}

Antonio G. Camacho: Conceptualization, Methodology, Software, Validation, Formal Analysis, Investigation, Writing-Original Draft, Writing-Review \& Editing, Funding acquisition. José Fernández: Conceptualization, Methodology, Software, Validation, Formal Analysis, Investigation, Writing-Original Draft, Writing-Review \& Editing, Project administration, Funding acquisition. Sergey V. Samsonov: Formal analysis, Investigation, Data curation, Writing-Review \& Editing. Kristy F. Tiampo: Formal Analysis, Investigation, Data curation, Writing-Review \& Editing. Mimmo Palano: Formal Analysis, Investigation, Writing-Review \& Editing. 